\title{
Attachment between brittle and ductile crust at wrenching plate boundaries
}

\author{
Ch. Teyssier ${ }^{1}$, B. Tikoff ${ }^{2}$, and J. Weber ${ }^{1}$ \\ ${ }^{1}$ Department of Geology and Geophysics, University of Minnesota, Minneapolis, MN 55455, USA \\ ${ }^{2}$ Department of Geology and Geophysics, University of Wisconsin, Madison, WI 53706, USA \\ ${ }^{3}$ Geology Department, Grand Valley State University, Allendale, MI 49401, USA
}

Received: 2 April 2001 - Accepted: 22 June 2001

\begin{abstract}
Using strain modeling we analyze the ductile deformation beneath rigid upper crustal blocks that rotate and translate in wrench zones. We define the zone of deformation as an attachment zone and assume strain continuity between the wrench shearing in the ductile crust and the horizontal shearing induced by the rotation/translation of rigid blocks. For reasonable amounts of rotation/translation of rigid blocks and reasonable thicknesses of attachment zones, the orientation and shape of the finite strain ellipsoids within attachment zones are calculated, and the orientation of planar and linear fabrics are predicted. Attachment zones beneath rotating blocks should display radiating foliation and concentric lineations; if rotation of rigid blocks is driven from below, deformation in the attachment zone is dominated by the wrench component, altering significantly the radiating and concentric patterns of foliation and lineation. Attachment zones beneath translating blocks display a wide range of foliation orientations, with steep foliations below the central part of rigid blocks, and gently dipping foliations toward the margins. Below the upper crustal strike-slip faults, foliation is shallowly dipping, strain intensity is maximum, and there is an abrupt reversal of sense of shear across a presumed discontinuity. The linear belt of greenschist-grade metamorphic rocks in Trinidad's Northern Ranges and eastern Venezuela's Paria Peninsula is a candidate for an exhumed attachment zone developed beneath translating upper crustal blocks during Neogene highly oblique convergence between the Caribbean and South America plates.
\end{abstract}

\section{Introduction}

Experimental work as well as field studies have demonstrated that the continental lithosphere is rheologically layered (Kohlstedt et al., 1995; Snoke et al., 1998). Under typical lithospheric conditions of deformation (geothermal gradient, strain rate), the main lithospheric layers are the brittle crust, the ductile crust, and the lithospheric mantle. The

Correspondence to: Ch. Teyssier (teyssier@umn.edu) brittle upper crust grades into the ductile lower crust across the brittle-ductile transition; the depth of this transition is defined mainly by temperature and strain rate which control the strength of materials deforming by crystal-plastic processes. This transition also coincides with the base of the seismogenic zone in the continental crust. The next major rheological boundary is compositional and located at the crust-mantle interface, across which rock strength increases substantially (Kohlstedt et al., 1995). Within the mantle lithosphere, rock strength decreases as a function of increasing temperature; at the base of the lithosphere, an abrupt weakening associated with the presence of partial melt in peridotite allows the lithospheric plates to move rigidly relative to the underlying mantle (Karato and Jung, 1998). There are probably many complications to this general lithospheric strength model introduced by subtle or abrupt changes in rock composition or by the presence of fluids (water, melt; e.g. Kohlstedt et al., 1995; Karlstrom and Williams, 1998). However, this fundamental three-layer lithosphere is a good first approximation. In a related paper in this volume, Tikoff et al. outline clutch tectonics and argue that there are subhorizontal deformation zones that couple, or "attach" the lithospheric layers. In this paper, we focus on the brittle-ductile transition zone in the crust and explore the structural implications of the "attachment" between rigid blocks and the underlying ductilely flowing crust for the cases of block rotation and translation along wrenching plate boundaries. We use strain modeling to predict the style, orientation, and kinematics of macroscopic fabrics associated with this transition zone, and compare our results to an attachment zone exposed in Trinidad and NE Venezuela, along the wrenching boundary between the South America and Caribbean plates.

\section{Wrench zones}

When subjected to deformation, lithospheric layers have a tendency to delaminate or slide relative to one another. Such behavior is well documented in regions of lithospheric contraction, where fold-thrust wedges form above décollements, 
as well as regions of lithospheric extension, where low-angle detachments develop. In this paper we focus on wrench or highly oblique plate boundaries, in which the zone of deformation is roughly orthogonal to the lithospheric layering (Molnar, 1992). By virtue of geometry and kinematics, lithospheric layers deformed in wrench zones maintain stable P-T conditions (Thompson et al., 1997), permitting large strain to accumulate under relatively constant conditions over long periods of time. Therefore, wrench zones are excellent settings in which to study the coupling between lithospheric layers. Along plate boundaries where continental crust is involved in wrenching, the zone of upper crustal deformation is diffuse (Molnar, 1988), commonly spread over widths of $100 \mathrm{~km}$ or more. This zone consists of a system of strikeslip faults separating crustal blocks that undergo translation and rotation. In addition, these intervening blocks may be internally deformed by folding, thrusting, and ductile flow (cataclastic flow and solution creep; Gratier et al., 1999).

Recent studies based on shear-wave splitting (Silver, 1996; Karato et al., 1998) demonstrate that the width of wrench deformation zones persists at depth into the mantle lithosphere, and possibly even the asthenosphere (Özaleybey and Savage, 1995; Molnar et al., 1999). Therefore, deformation at wrenching plate boundaries is diffuse not only in the crust, but also in the mantle. Because displacement fields in the upper crust are discontinuous, whereas those in the mantle are likely continuous, the ductile lower crust probably accommodates this difference and undergoes complex flow (Teyssier and Tikoff, 1998; Tikoff et al., this volume).

\section{Concept of attachment zones}

In wrench settings, the upper crust consists of relatively rigid blocks that translate and rotate along strike-slip faults. A key question about strike-slip systems is the nature of deformation below these rigid blocks. This issue was well laid out by Sylvester's (1988) discussion of mechanical stratigraphy in wrench zones. The details of deformation in the zone below the rigid blocks depends on whether the system is driven from above or from below (Tikoff and Teyssier, 1994; Tikoff et al., this volume). We define the zone of deformation at the base of rigid blocks as an "attachment zone" (Tikoff et al., this volume) that preserves strain continuity, rather than a detachment, where strain continuity is lost. This distinction is important because if rigid blocks are translated and rotated by coupling to the lower crust and mantle, structures should be produced that reflect this process. By modeling strain in attachment zones, we make predictions about the ductile fabrics that may develop in this region of the crust. Those model predictions should be useful guides in interpreting structures in exhumed, ductilely deformed wrench terranes suspected to have developed below rigid blocks. In this paper, we address general principles of deformation associated with the rotation and translation of rigid blocks above a ductilely deforming crust. We use simple strain modeling to predict the orientation of ductile fabrics as well as the style and magnitude of deformation in attachment zones. Finally, we propose as a working hypothesis that, along the Caribbean-South America plate boundary, Paria Peninsula (Venezuela) and Trinidad's Northern Range expose an exhumed attachment zone developed at the base of the brittle crust during oblique convergence between the two plates.

\section{Rotation of rigid blocks}

Figure 1 captures several different possible scenarios for block rotation and deformation in a ductile layer beneath: (1) rotation of a rigid block above an actively deforming zone; (2) rotation of a rigid block above a passive ductile layer; and (3) passive rotation of a rigid block above a deforming ductile layer. In this figure, we highlight the local sense of shear expected in the attachment zones in each scenario (Fig. 1a), to illustrate the differential motion between the brittle and ductile crust for these three particular cases (Fig. 1b). The kinematics of a flat-lying attachment zone between a rigid block and the underlying ductile layer depends on the local differential motion between these two layers. The motion of the rigid block is simply described by a rotation about a vertical axis, whereas motion in the underlying layer is described by simple shearing, with a radial shear gradient. It is instructive to compare the instantaneous rotation of horizontal material lines in the ductile wrench zone with similarly oriented lines in the rigid block, because the differential rotation of these lines dictates the main characteristics of deformation in the attachment zone, including sense of shear (Fig. 1b).

In case 1, both the rigid block rotation and the ductile layer deformation are driven from the sides. The rigid upper block rotates at velocity w. Simultaneously, the ductile layer deforms at a shear strain rate consistent with w: a full revolution $\left(360^{\circ}\right)$ of the rigid block takes place after a finite shear strain of $\pi$ in the wrench zone. In the rigid block, all diameter lines rotate at the full velovity w; however, in the underlying ductile wrench zone, material lines stretch and rotate at various velocities depending on their orientations (e.g. Ramsay and Huber, 1983). Lines oriented parallel to the shear zone (E-W in the example shown) do not rotate; therefore, clockwise rotation of the rigid block always imparts a topto-south and top-to-north sense of shear in the eastern and western regions, respectively, of the attachment zone. In the northern and southern parts of the attachment zone, material lines in both the rigid block and the underlying ductile layer rotate at the same velocity. Hence, no differential shear motion is taking place, other than that due to the difference in displacement caused by stretching of lines in the ductile layer (Fig. 2). Therefore, a shear gradient exists within the attachment zone; the strongest effect is in the central part of the ductile shear zone, beneath the E-W diameter of the rigid block.

In case 2 , the rigid block rotates above a passive ductile layer in which material lines do not rotate. Consequently, shearing in the upper part of the ductile layer is entirely due 


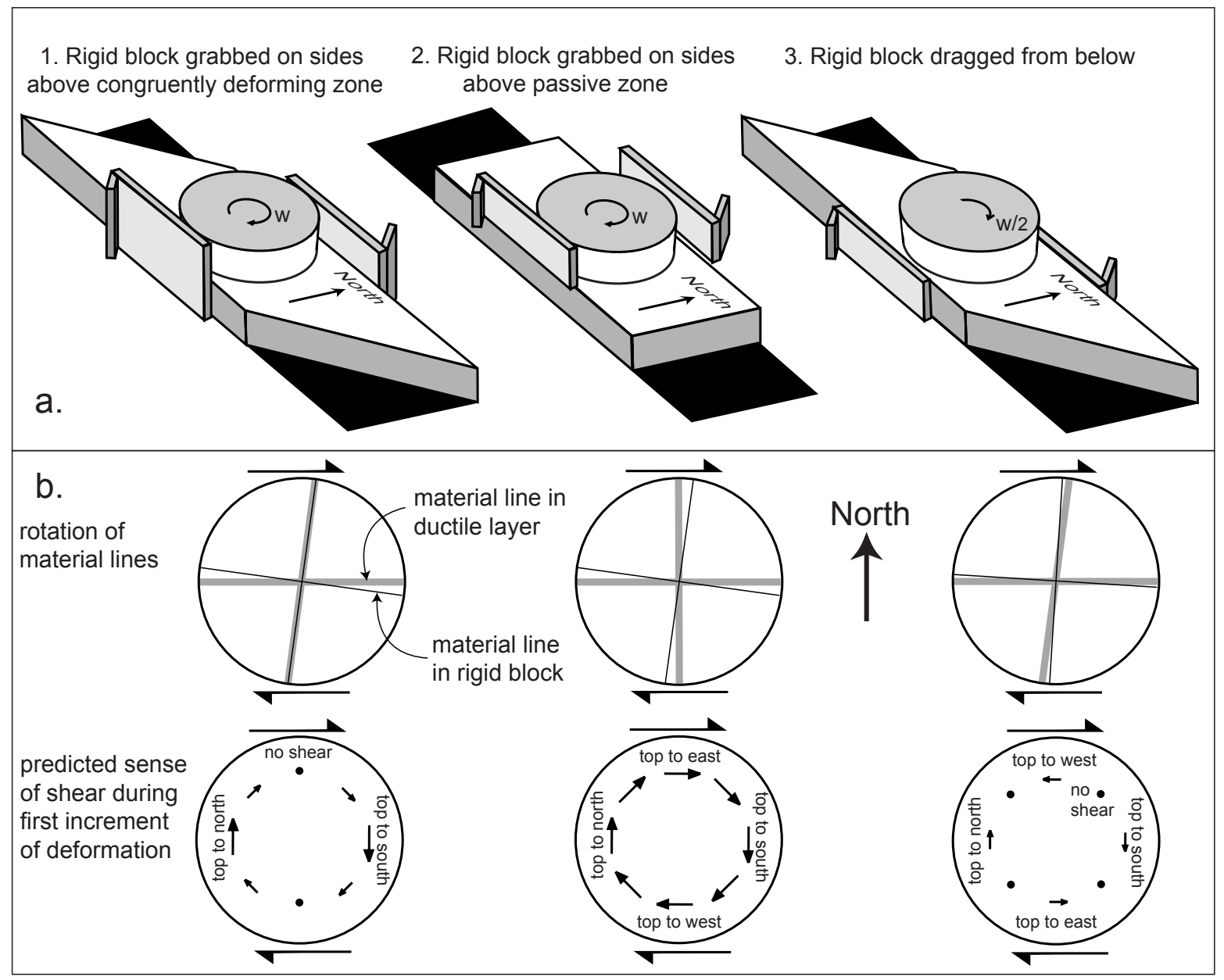

Fig. 1. (a) Three hypothetical scenarios of wrench zones involving rotation of a cylindrical rigid block above a ductile layer. Rigid blocks "grabbed from the sides" (cases 1 and 2) rotate at velocity w determined by the shear strain rate; a full revolution of the block takes place every $\gamma=\pi$. In case 1 , both the brittle and ductile layers deform, driven by side boundary conditions. Although they have the same overall strain rate, the rigid block is characterized by vertical-axis rotation, while the ductile layer deforms homogeneously in wrench; in case 2 the rigid block rotates above a passive zone, i.e. deformation is imposed from above. In case 3, the rigid block is passively dragged from below by flow in the ductile layer; in this case, the rotation velocity is w/2 for the same shear strain as case 1 . (b) Map views of the effect of the rotating rigid block on deformation in the horizontal "attachment zone" for cases 1-3, showing incremental rotation of material lines in rigid block and ductile layer and associated sense of shear. Arrows represent sense of shear in the horizontal attachment zone; sense of shear is also given in geographic coordinates for a wrench zone oriented E-W. In case 1, a tangential shear gradient develops; N-S material lines in the ductile layer rotate at the same velocity as the rigid block (no shear), and E-W material lines do not rotate, imparting a horizontal shear with top-to-south in the east and top-to-north in the west. In case 2, no tangential shear gradient develops because the ductile layer is not actively deforming, but a radial shear gradient does develop in the attachment zone. In case 3, N-S material lines rotate clockwise twice as fast as the rigid block, resulting in a top-to-west and top-to-east sense of shear in the northern and southern regions, respectively; E-W material lines in the ductile layer do not rotate, resulting in a top-to-south and top-to-north sense of shear in the east and the west, respectively. See text for further discussion.

to rotation of the upper block, and the amount of shearing in the attachment zone depends only on position from the center of the rotating rigid upper block: the farther from the center, the higher the shear strain.

In case 3, the rigid block rotates as a result of shearing of the lower ductile layer beneath it. This is equivalent to passive rotation of a circular object embedded in a ductile matrix, which was investigated by Ghosh and Ramberg (1976). As a result of the flow beneath, the upper rigid block rotates at a velocity w/2. Consequently, the attachment zone fabric forms from the combination of pervasive wrenching and by drag of the rigid upper block on the lower ductile layer. Material lines in the northern and southern regions of the ductile layer rotate at twice the velocity of the rigid block, resulting in a local sense of shear opposite to that in case 1 . In the eastern and western regions, material lines in the ductile layer do not rotate and the block rotates clockwise, resulting in the same relation as shown in case 1 , but with half the shear strain rate. 


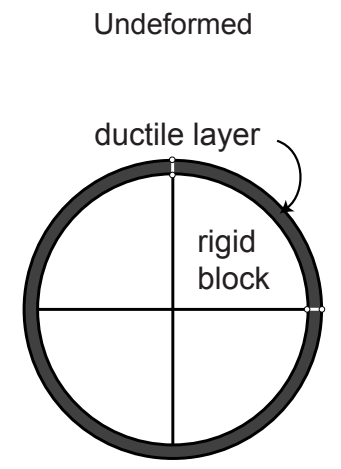

a.
Rigid block grabbed on sides above congruently deforming zone

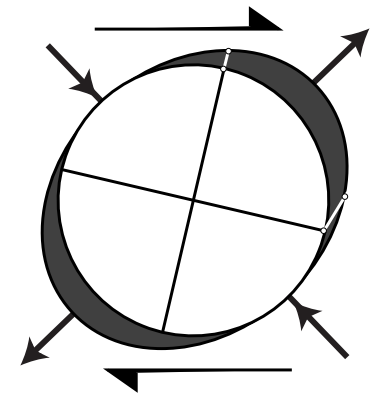

b.
Rigid block dragged from below

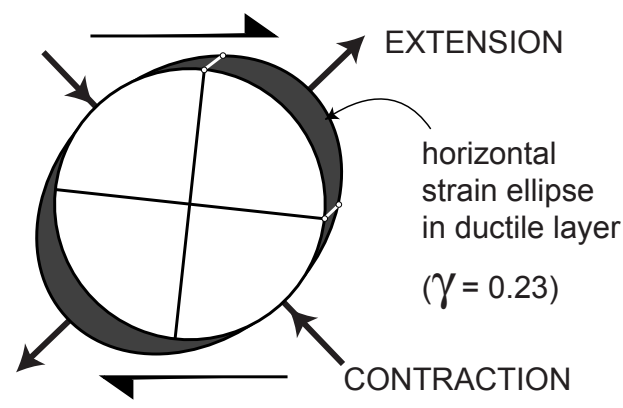

C.

Fig. 2. Map view of base of rigid block and underlying ductile layer (grey) deforming in wrench zone. (a) undeformed state; white lines join two material points (in the N-S and E-W vertical planes), one at base of rigid block and the other at some depth in the homogeneously deforming wrench zone. (b) and (c) after one increment of strain $(\gamma=0.23)$, rigid block has rotated, according to the two cases shown in Fig. 1, and ductile layer has deformed in wrench according to the horizontal strain ellipse. Strain compatibility imposes a gradient of deformation (in attachment zone) between the base of the rigid block and the wrench zone at depth; changes in orientation and length of white lines demonstrate the effect of both rotation and stretch.
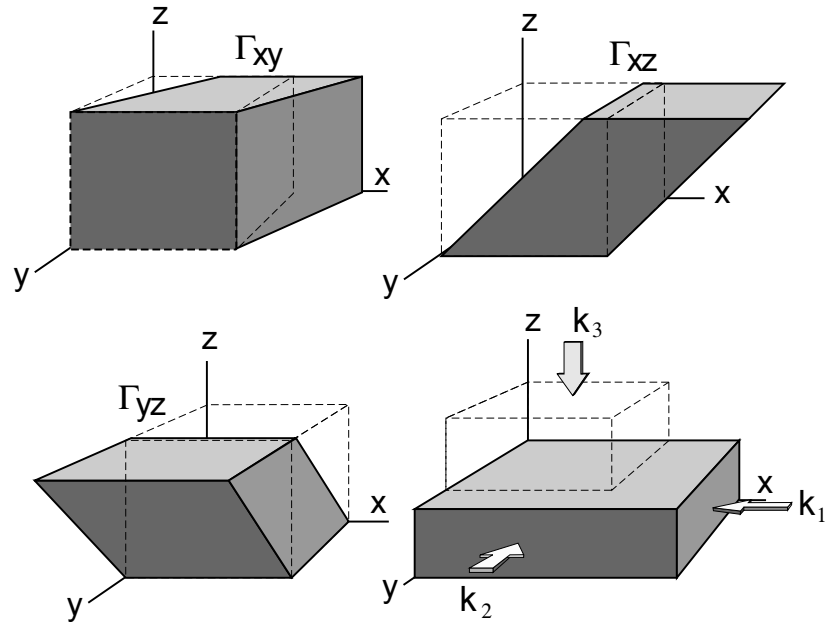

Fig. 3. Graphical representation of deformation matrix parameters (after Fossen and Tikoff, 1993). Combinations of simple shear and coaxial strain can produce any homogeneous deformation. Strain in attachment zones beneath rotating blocks was calculated using the wrench simple shear and various combinations of $\Gamma_{x z}$ and $\Gamma_{y z}$.

Deformation in the attachment zone underneath rigid blocks is controlled by the differential rotation of material lines in the rigid block and the underlying ductile layer, but also by the differential stretches of material lines. By definition, material lines in the rigid block do not stretch, whereas material lines in the ductile layer stretch according to simple shearing. Figure 2 illustrates the infinitesimal stretches (extension and contraction) underneath the rigid blocks and therefore the expected motion in the various portions of the attachment zone. The stretching from beneath will create stresses within the rigid block, possibly leading to deformation (fracturing, folding) of the "rigid" block.

\subsection{Finite strain and structures in attachment zone}

In this section, we explore the deformation and expected structural style of attachment zones beneath rotating rigid blocks, using analytical strain solutions. This strain modeling uses the deformation-matrices approach published in Tikoff and Fossen (1993) and a version of the 3D-STRAIN program (Tikoff and Fossen, 1996). 3D-STRAIN uses an upper triangular deformation matrix; we do not need to account for a "spin" component because the deformation we prescribe involves no external rotation of coordinate axes. The deformation matrix used is given by:

$$
\left[\begin{array}{ccc}
\mathrm{k}_{1} & \Gamma_{\mathrm{xy}} & \Gamma_{\mathrm{xz}} \\
0 & \mathrm{k}_{2} & \Gamma_{\mathrm{yz}} \\
0 & 0 & \mathrm{k}_{3}
\end{array}\right]
$$

where $\mathrm{k}_{1}, \mathrm{k}_{2}$, and $\mathrm{k}_{3}$ are the coaxial components applied along $\mathrm{x}, \mathrm{y}$, and $\mathrm{z}$, respectively. $\Gamma_{\mathrm{xy}}, \Gamma_{\mathrm{xz}}$, and $\Gamma_{\mathrm{yz}}$ are the simple shear components representing a wrench shear in the $\mathrm{x}$ direction, a horizontal shear in the $\mathrm{x}$-direction, and a horizontal shear in the y-direction (shown graphically in Fig. 3). This general deformation matrix allows superposition of orthogonal simple shears and coaxial strain. For the cases studied here, we used various combinations of simple shears in order to model appropriate directions of horizontal shear (by combining $\Gamma_{\mathrm{xz}}$ and $\left.\Gamma_{\mathrm{yz}}\right)$ and wrenching $\left(\Gamma_{\mathrm{xy}}\right)$. The modeling output consists of orientations of the finite strain axes, shape of the finite strain ellipsoid, and finite stretches.

The simplest case is case 2 (Fig. 1), where the deformation in the ductile crust is controlled by block rotation alone, without any wrenching. In this case, for a given thickness of attachment zone, the strain ellipsoid at each point of an attachment zone is consistent with a horizontal simple shear in a direction normal to the radius and with a sense consis- 
tent with block rotation. For a finite block rotation $\pi / 2\left(90^{\circ}\right)$, the shear strain in a small volume of an attachment zone of thickness $\mathrm{A}$ at a distance $\mathrm{r}$ from the rotation axis is $\pi \mathrm{r} / 2 \mathrm{~A}$, assuming strain is homogeneous over the thickness of the attachment zone (Fig. 4a). The shear strain at a distance $\mathrm{r} / 2$ from the center of the block is $\pi \mathrm{r} / 4 \mathrm{~A}$. These values are critically dependent on the thickness A of the attachment zone, which can be expressed as a fraction of $\mathrm{r}$. For a reasonable value of $\mathrm{A}=\mathrm{r} / 2$, the shear strain at a distance $\mathrm{r}$ from the center is $\pi$; at $r / 2$, the shear strain is $\pi / 2$. For $A=r$, the shear strain at a distance $r$ from the center is $\pi / 2$. Assuming that foliation and lineation correspond to the $S_{1} S_{2}$ principal plane and $S_{1}$ principal axis, respectively, of the finite strain ellipsoid, their orientations are given as model output. For case 2 (Fig. 1), foliation in the attachment zone should be striking radially and dipping moderately to shallowly away from the sense of rotation, with dip angle decreasing as a function of finite block rotation; lineation should form concentric patterns centered on the rotation axis (Fig. 4). For a finite block rotation of $\pi / 2$, and an attachment zone thickness of $r / 2$, foliation at a distance $\mathrm{r}$ from the center dips $16^{\circ}$, and $26^{\circ}$ at a distance $r / 2$. The shape of the finite strain ellipsoid corresponds to plane strain everywhere.

Figure 5 shows the results of strain modeling for cases 1 and 3 (Fig. 1), assuming a finite block rotation of $90^{\circ}(\pi / 2)$ and an attachment zone of thickness $\mathrm{r} / 2$. In case 1 (Fig. 1), deformation in the attachment zone is controlled by a combination of wrenching and horizontal shear. For a given thickness of an attachment zone (here $\mathrm{r} / 2$ ), the wrench shear and the horizontal shear are coupled (Fig. 5a). A finite block rotation of $\pi / 2$ corresponds to a wrench shear strain $\gamma=\pi / 4$ (Fig. 5b). At a distance $r$ from the block center, the horizontal shear is $\gamma \mathrm{r} / 2 \mathrm{~A}$, like in case 2 treated above (Fig. 4a). The average strain in vertical domains of the attachment zone at radii $r$ and $r / 2$ was calculated and again mapped as foliation and lineation (Figs. 5c,d). Because of compatibility, strain must be heterogeneous in the attachment zone, not only due to the radial dependence of strain, but also because foliation should merge downward into the vertical wrench zone foliation. The manner in which this merging takes place is controlled by the rheology of the material comprising the attachment zone. Here we do not take rheology into account; we simply calculate bulk finite strain assuming no vertical strain gradients in the attachment zone. This approach is only semiquantitative, but gives a fairly accurate representation of lateral strain variations within this sort of attachment zones.

For the case 1 (Fig. 1) scenario, Fig. 5c shows that foliation strikes more or less radially, particularly in the NE and SW quadrants of the attachment zone. In these regions, strain ellipsoids formed in response to the wrench component and the horizontal shear component share a similar strike. Foliation dips $13-21^{\circ}$ at radius $r$, and $20-34^{\circ}$ at $r / 2$, a substantial deviation from the vertical foliation formed in the wrench zone beneath. These results, as well as the fact that the lineation patterns are close to concentric, show that horizontal shear dominates over wrenching, even in regions located closer to the rotation axis (e.g. at a radius $r / 2$ ). This is to be expected

\section{a. Shear strain in attachment zone}

$$
\gamma=\tan \psi=\pi r / 2 \mathrm{~A}
$$
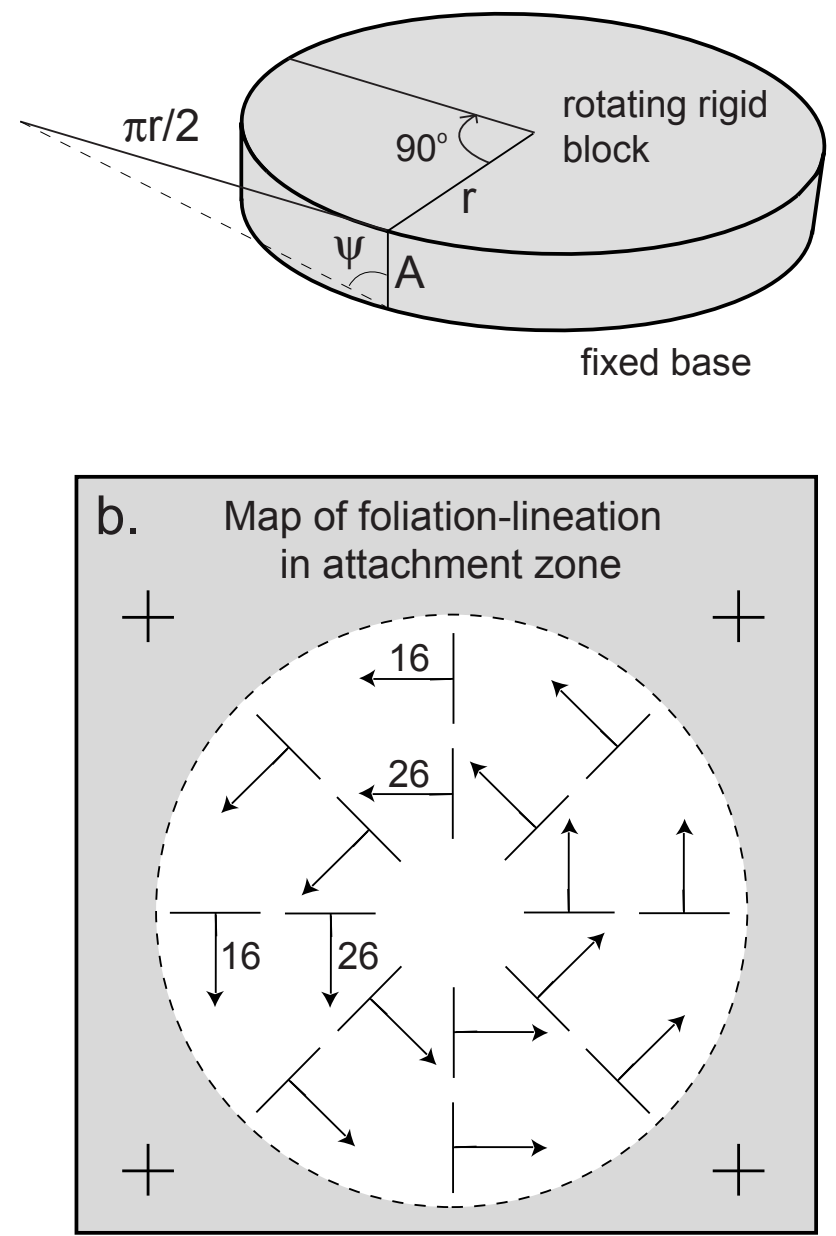

Fig. 4. (a) Deformation in the attachment zone under a rigid block rotating above a passive ductile layer (case 2, Fig. 1). During a $90^{\circ}$ rotation, finite shear strain in a small volume of attachment zone located at $r$ from the block center corresponds to $\pi \mathrm{r} / 2 \mathrm{~A}$ (A: thickness of attachment zone). (b) Results of strain modeling of attachment zone presented as calculated foliation and lineation $\left(S_{1}-S_{2}\right.$ principal plane and $S_{1}$ principal axis of the finite strain ellipsoid, respectively). Foliation is oriented radially, and lineation forms a concentric pattern.

because horizontal shearing is 4 times greater than wrenching at a radius $r$, and 2 times greater at $r / 2$. The shape of the finite strain ellipsoid is plane strain along the N-S and E$\mathrm{W}$ diameters of the attachment zone, reflecting the fact that superposition of two orthogonal simple shears produces another simple shear, and therefore plane strain. Flattening occurs in the NE and SW quadrants, and constriction occurs in the NW and SE quadrants. In the NE quadrant, for example, the wrench strain ellipsoid is elongated E-NE with a horizontal long axis and a vertical intermediate axis. Adding a horizontal shear in a SE direction tends to rotate and elongate this intermediate axis, producing a flattening strain. In 
a. Undeformed state

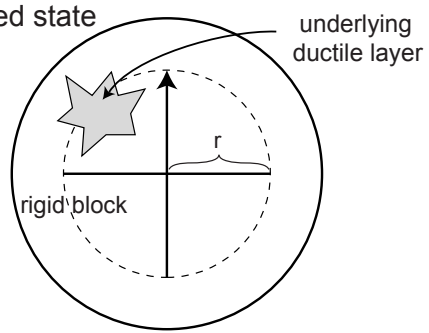

b. Relationship between wrench shear strain and $90^{\circ}$ block rotation in cases 1 and 3 (Fig. 1) $\quad \gamma=\pi / 4$

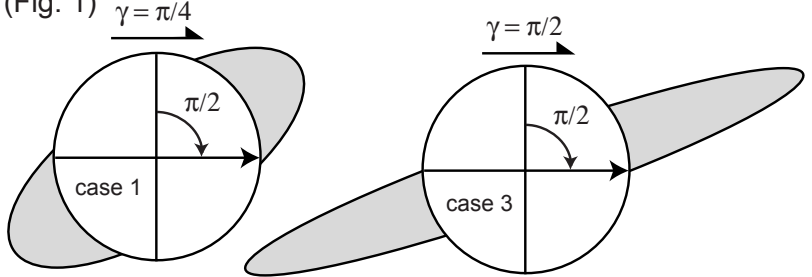

C. case 1 (Fig. 1): Rigid block grabbed on sides above congruently deforming zone

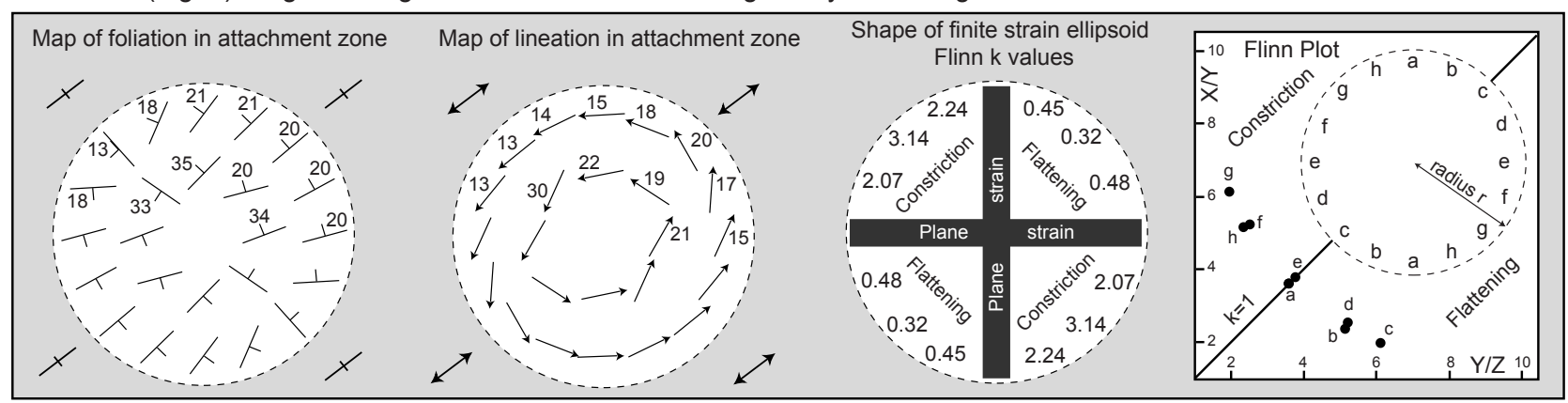

d. case 3 (Fig. 1): Rigid block dragged from below

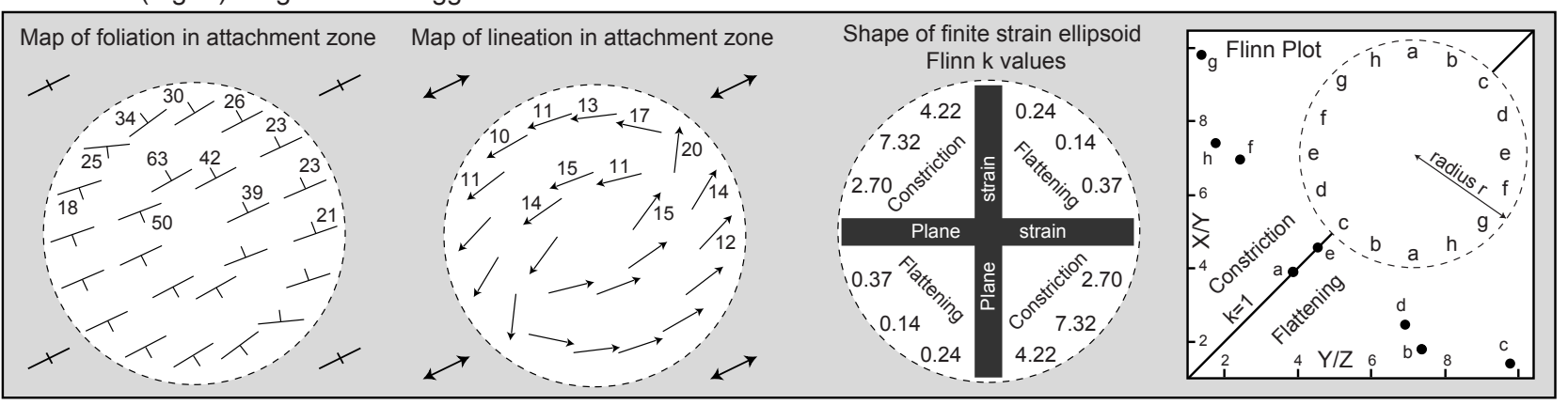

Fig. 5. Deformation in the ductile layer (attachment zone) under a rotating rigid block. (a) starting configuration in map view, showing the position of vertical markers from the bottom of the rigid layer to the base of the attachment zone, where the strain is controlled by pure wrenching; (b) $90^{\circ}$ rotation of rigid block and finite strain in wrench zone at depth (grey ellipse) for cases 1 and 3 (Fig. 1); strain in attachment zone reflects both boundary conditions and varies with depth; (c) results of modeling of depth-averaged finite strain in the attachment zone, presented as calculated foliation and lineation $\left(S_{1} S_{2}\right.$ principal plane and $S_{1}$ principal axis of finite strain ellipsoid), Flinn parameter $\mathrm{k}=\left[\left(\mathrm{S}_{1} / \mathrm{S}_{2}\right) /\left(\mathrm{S}_{2} / \mathrm{S}_{3}\right)\right]$, and shape of finite strain ellipsoid shown in Flinn plot. Model assumes a $90^{\circ}$ finite rotation of the rigid block, corresponding to a $\pi / 4(\gamma \sim 0.785)$ and a $\pi / 2(\gamma \sim 1.57)$ shear strain in the wrench zone for cases 1 and 3 (Fig. 1), respectively. Deformation in the attachment zone is achieved by the combination of two shear strains: vertical shear strain consistent with the wrench component and horizontal shear strain related to rigid-block rotation; this horizontal shear component is applied to an attachment zone of constant thickness $\mathrm{r} / 2$; for a block $20 \mathrm{~km}$ in diameter, the attachment zone is $5 \mathrm{~km}$ thick). Results show that shallowly inclined foliation and lineation are dominated by the horizontal shear at the base of the rigid block; steepening of foliation toward the center is related to the smaller horizontal shear strain (shear strain inceases linearly with radius and is zero at center of block); flattening and constrictional fabrics develop in quadrants separated by zones of plane strain.

the SE quadrant, horizontal shearing tends to further elongate the ellipsoid long axis produced by wrenching, resulting in a constrictional strain. The minimum and maximum Flinn $\mathrm{k}$ values of 0.32 and 3.14 indicate that, for a finite block rotation of $\pi / 2$, substantial deviation from plane strain occurs (Flinn plot, Fig. 5c).

In the case 3 scenario (Fig. 1), where a rigid block is dragged from below, the rotation rate of the rigid block is half that developed in case 1; therefore, it takes a wrench shear strain twice as large in the ductile layer to achieve the same finite block rotation of $\pi / 2$ (Fig. $5 b$ ). Results of strain modeling are shown in Fig. 5d. Compared to case 1, the foliations strike more consistently in the direction of the wrench-produced foliation outside the attachment zone. Foliation dips range from $18^{\circ}$ to $34^{\circ}$ at radius $r$, and $39^{\circ}$ to $63^{\circ}$ at $r / 2$. Lineations are less concentric than in case 1 and are also typically shallower, showing again the greater influence of wrenching from below. The finite strain ellipsoid shows a similar distribution of flattening and constrictional shapes as in case 1 , but with more extreme values of $\mathrm{k}(0.14$ to 7.32$)$. In 


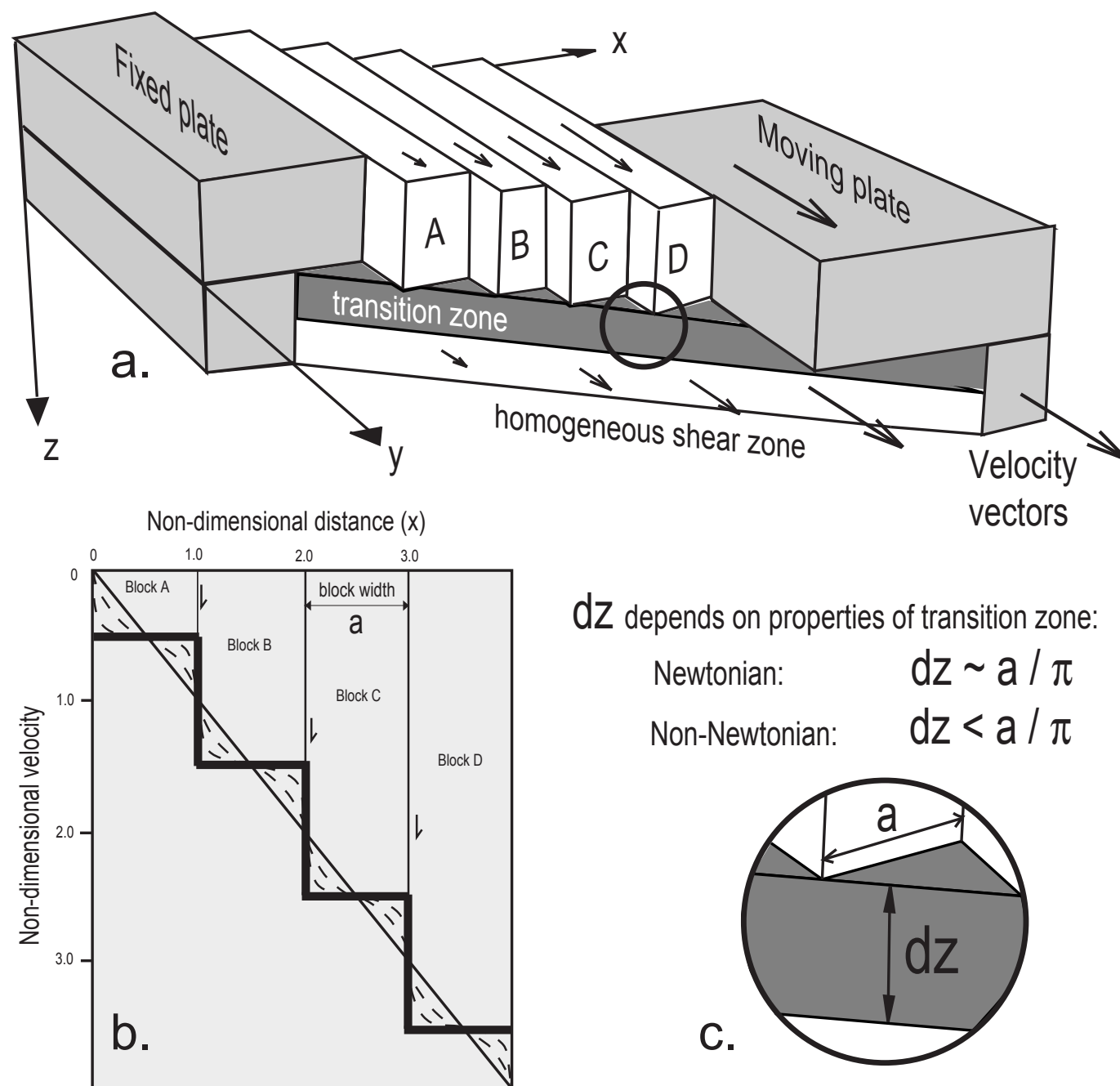

Fig. 6. (a) Behavior of layered crust in wrench zones: Upper crustal blocks are translated above a homogeneous shear zone; a transition zone accommodates the difference in velocities (after Bourne et al., 1998a). (b) Map view of velocity field, showing the transition from a staircase pattern of velocities in the translating blocks to simple shear at depth; in the transition zone the velocity field is described by sinusoidal functions that vary with depth from high amplitude to low amplitude (Bourne et al., 1998a). (c) Detail of transition zone (as shown in (a)), showing its thickness $d z$ as a function of block width $a$; for Newtonian fluids, $d z \sim a / \pi$, and for non-Newtonian fluids, $d z<a / \pi$ (Bourne et al., 1998a); the transition zone is the zone of attachment studied in this paper.

the NW and SE quadrants, an abrupt switch of foliation dip occurs from $25^{\circ} \mathrm{S}$ to $34^{\circ} \mathrm{NW}$, creating an antiform of foliation. This "switch" is related to the strong constrictional fabric and rather unstable planar fabric in these quadrants (see also Flinn plot, Fig. 5d).

\subsection{Application of models}

Criteria that can be used to recognize exhumed attachment zones that formed beneath rotating rigid blocks include consistently-oriented vertical fabrics at depth which change upward into a pattern of radial foliation with relatively shallow dips and concentric lineations. Such attachment zones should also show wide variations in the shape of the finite strain ellipsoid, from flattening to constriction, broadly distributed in quadrants that are symmetric about the rigid block rotation axis. The difference between the attachment zones developed in cases 1 and 3 scenarios is subtle. With passive block rotation (case 3 ) the strike of foliation is relatively consistent with that produced by wrench deformation beneath, and the flattening/constrictional fabrics are extremely pronounced.

An assumption made in the strain calculations is that the thickness of the attachment zone is constant beneath the rotating blocks. This assumption is justified because the crust is rheologically layered, and the rheology of the ductile crust is dependent mainly on temperature which increases gradually with depth. Therefore, it is conceivable that a ductile layer of a given thickness and relatively constant rheology could control the location and thickness of the attachment zone and permit horizontal strain gradients to accumulate there. Alternatively, one could envision that the thickness of attachment 


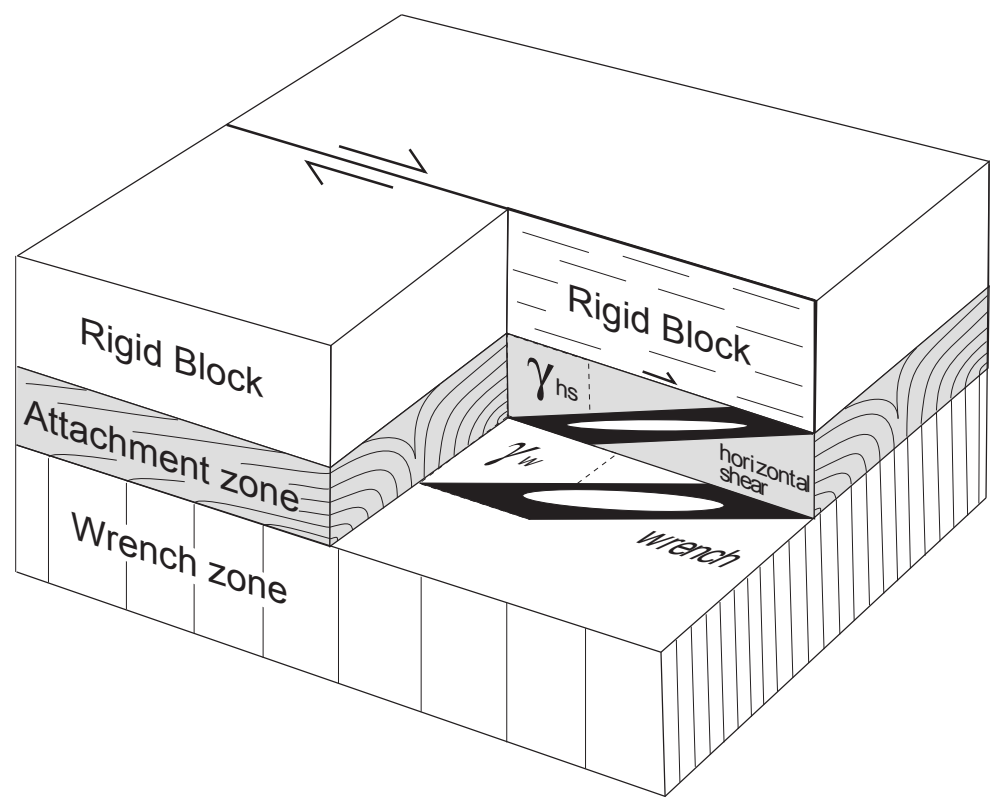

Fig. 7. Schematic block diagram of the two shear components in the attachment zone. In addition to the wrench shear $\gamma_{\mathrm{w}}$ due to wrenching in the ductile layer, a horizontal shear $\gamma_{\mathrm{hs}}$ is generated by the horizontal displacement of the rigid blocks during translation. The thinner the attachment zone, the higher the horizontal shear strain. The horizontal shear varies laterally from zero below the center of the blocks, to maximum below the blocks margins; therefore, gently dipping fabrics are expected to form below the strike-slip faults in the upper crust.

zones is related mainly to the infinitesimal strain or strain rate imposed by block rotation, which varies radially. In this case, the attachment zones would be thickest at block margins, and thinnest near block centers. This variation would have the effect of suppressing the radial strain gradients.

The models studied above are ideal cases of circular rigid blocks, which approximate some natural examples of blocks that are relatively equant or close to square in map view; the Central Mojave Block and the Eastern Transverse Ranges Block in southern California are possible examples (Luyendik et al., 1980). However, many rotated crustal blocks have an elongate shape with aspect ratios on the order of 3:1 or 4:1, including the Western Transverse Ranges and Catalina Blocks (Sylvester, 1988). Rotation of such elongated blocks above an attachment zone would result in different strain patterns from those predicted here, although the overall trends would be similar. The conceptual background presented above should be used with caution, and only as a guide, to interpret wrench tectonics in regions where attachment zones beneath rotated blocks are suspected.

\section{Translation of rigid blocks}

Bourne et al. (1998 a,b) studied the translation of crustal blocks above a homogeneously shearing viscous layer (Fig. 6). They matched model velocities of "floating" blocks separated by discrete faults to observed values measured geodetically in the Marlborough fault system in New Zealand and the San Andreas system in southern California. They found that the present-day (i.e. geodetic) velocity field of the translating upper crustal blocks corresponds well with the long-term, average velocity field determined from geological studies and relative plate motion. Therefore, they suggested that the upper crustal blocks are dragged passively from beneath by a viscously shearing lithospheric mantle, an inference similar to that derived from earlier studies of block rotation (England and Wells, 1991). Savage et al. (1999), however, using the same data, argued that Bourne et al.'s (1998a) claims were inconclusive, because a viscoelastic coupling model, which explicitly describes fault behavior with seismic event and interseismic loading, also produces a good match to the observed velocities. Because the two different models predict similar results, the geodetic data cannot uniquely support either. The discrepancy hinges mainly on whether deformation measured on a geodetic time scale is elastic as opposed to permanent.

Irrespective of the precise model chosen, some form of mechanical coupling must exist between the strong lower and upper layers of the lithosphere during deformation, and this coupling must take place in the ductile crust. The mechanical basis for such thinking was outlined in Molnar (1992) who proposed that the strength of the ductile layer within broad wrench zones was sufficient to transfer motion from a shearing upper mantle to a brittle upper crust. Although the mechanics of the ductile crust in wrench zones cannot be completely constrained from the kinematics of the upper crustal blocks, some predictions can be made. If the rigid blocks are translated above a shearing lower lithosphere, and the ductile crust is modeled as a Newtonian fluid, then the thickness of the coupling zone is related to the width of the individual crustal blocks. A solution to Laplace's equations 

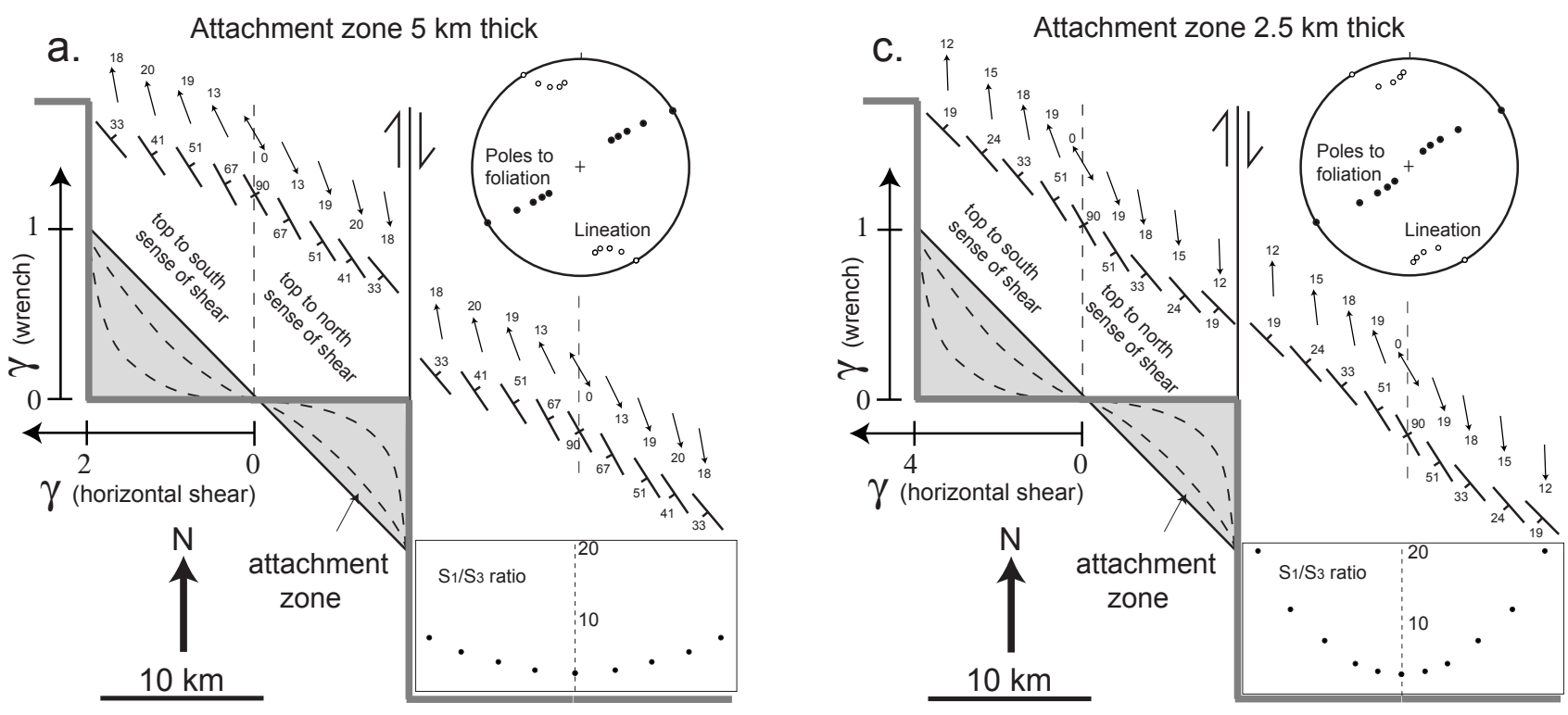

b.
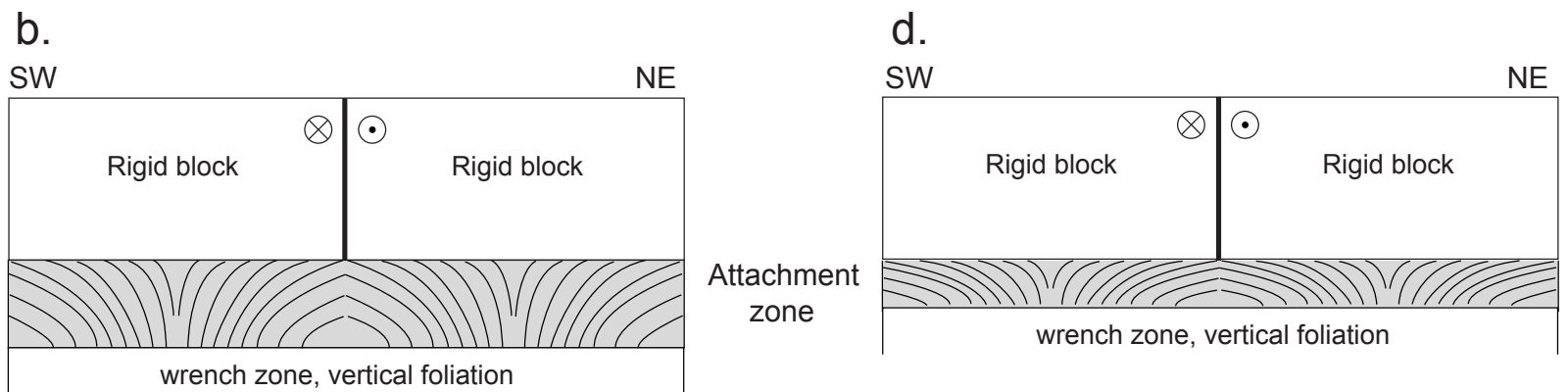

Fig. 8. (a) and (c) Maps of calculated foliation and lineation in attachment zone ( $5 \mathrm{~km}$ and $2.5 \mathrm{~km}$ thick, respectively) beneath translated rigid blocks. "Foliation" and "lineation" are calculated from the strain axes and are the $S_{1} S_{2}$ principal plane and $\mathrm{S} 1$ principal axis, respectively of the finite strain ellipsoid. Thick grey staircase line represents the edges of rigid blocks; dashed line is the median line of the rigid blocks. For $\gamma_{\mathrm{w}}($ wrench $)=1, \gamma_{\mathrm{hs}}$ (horizontal shear) varies from below the center to below the edges of the blocks, from 0 to 2 if the attachment zone is $5 \mathrm{~km}$ thick, and from 0 to 4 is the attachment zone is $2.5 \mathrm{~km}$ thick. Results of strain modeling show that foliation is steeply dipping in the region below the center of the block, and that dips become shallower toward the edges of the blocks. Lineation plunges shallowly; sense of shear along the lineations is reversed abruptly between the attachment of one block and the other. Strain intensity is plotted as S1/S3 ratio, showing finite strain increase toward the block margins. (b) and (d) Tentative cross sections drawn roughly perpendicular to foliation strike, showing the antiformal attitude of foliation, with a fan geometry below the center of blocks.

shows that the velocity field within horizontal planes at some depth below the rigid blocks is sinusoidal, with the amplitude of the sinusoid decreasing as the velocity field approaches that of simple shear in the homogeneously deforming layer at depth (Bourne et al., 1998b). In addition to block width, the thickness of the deforming zone depends on material properties. For a block of width $\mathrm{a}=20 \mathrm{~km}$ the deformation zone in a Newtonian fluid would be $\mathrm{a} / \pi \sim 6 \mathrm{~km}$ thick (Bourne et al., 1998a) (Fig. 6). For a non-Newtonian fluid of powerlaw rheology the predicted thickness of the deforming zone is less than $\mathrm{a} / \pi$ because deformation tends to localize.

We present the results of strain modeling of a ductile layer deforming beneath long rigid blocks that translate along a wrench margin. The ductile layer deforms in wrench shear at depth, but changes upward to an attachment zone that cou- ples the wrenching to the motion of the rigid blocks (Fig. 7). For the purpose of the model calculations, we use an attachment zone with a fixed thickness which accommodates the product of two shear components: a wrench $\operatorname{shear}\left(\gamma_{\mathrm{w}}\right)$ applied from the bottom, and a horizontal shear $\left(\gamma_{\mathrm{hs}}\right)$ related to the displacement of the rigid blocks at the top (Fig. 7). The combination of wrench and horizontal shear (combination of $\Gamma_{\mathrm{xy}}$ and $\Gamma_{\mathrm{xz}}$, Fig. 3), without a coaxial component of deformation, results in an inclined simple shear zone with movement parallel to the x-axis (Fossen, 1993; Merle and Gapais, 1997). We conduct two sets of simulations, one with relatively low wrench displacement $\left(\gamma_{\mathrm{w}}=1\right)$ (Fig. 8), and the other with larger wrench displacement $\left(\gamma_{\mathrm{w}}=3\right)$ (Fig. 9), and explore the predicted fabric strengths and orientations. In the first case, rigid blocks have a width $\mathrm{a}=20 \mathrm{~km}$ and are trans- 


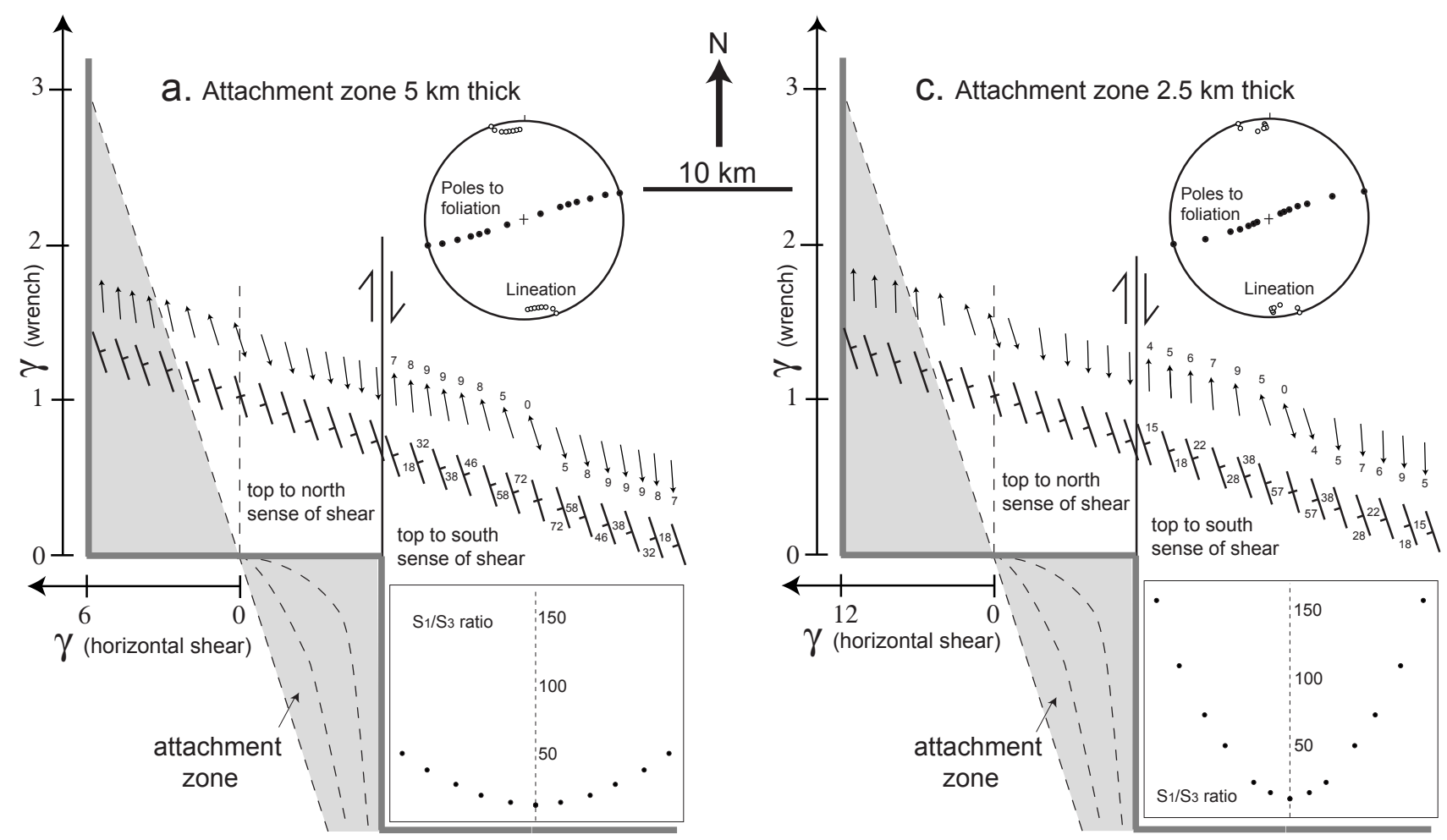

b.

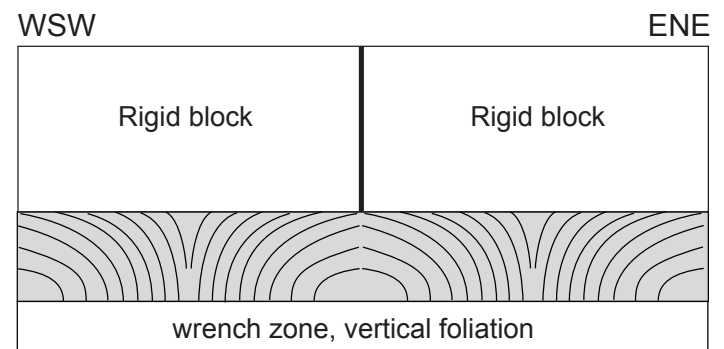

d.

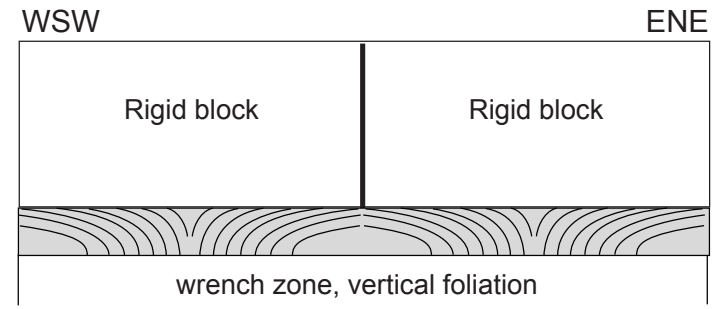

Fig. 9. Same as Fig. 8, but with $\gamma_{\mathrm{w}}($ wrench $)=3$, larger strike-slip motion between rigid blocks, and therefore larger shear strain in attachment zone. Strain intensity is plotted as S1/S3 ratio, showing dramatic increase toward the block margins. See text for discussion.

lated by $20 \mathrm{~km}$ of strike-slip faulting. At depth, the wrench zone deforms homogeneously and has achieved a shear strain $\gamma_{\mathrm{w}}=1$, consistent with $20 \mathrm{~km}$ of strike-slip faulting in the upper crust (Fig. 8). Strain is calculated for two attachment zone thicknesses, $\mathrm{A}=5 \mathrm{~km}$ and $\mathrm{A}=2.5 \mathrm{~km}$, which correspond to $1 / 4$ to $1 / 8$, respectively, of the rigid block width, and are consistent with theory that predicts that $\mathrm{A}<\mathrm{a} / \pi$ for power-law rheologies (Bourne et al., 1998a). We assume a velocity field that changes gradually with depth, as illustrated by the sinusoidal curves at various depths of the attachment zone (Fig. 8). The horizontal shear component increases from the central part of the block, where it is zero, to the margin of the block, where it is at a maximum and depends on the amount of strike-slip faulting and on the thickness of the attachment zone. At any location within the attachment zone, the total strain is the product of horizontal shear and wrench shear; therefore strain is heterogeneous and reflects the torque that takes place under the moving rigid blocks.
This torque is produced by the two components of simple shear, $\gamma_{\mathrm{hs}}$ and $\gamma_{\mathrm{w}} ; \gamma_{\mathrm{w}}=1$ everywhere, and $\gamma_{\mathrm{hs}}$ varies from the block center, where it is zero, to the margins where it is maximum. These two simple shears are coupled through the thickness of the attachment zone; if $\gamma_{\mathrm{w}}=1$, and the attachment zone is $5 \mathrm{~km}$ thick, $\gamma_{\mathrm{hs}}$ must vary between 0 and 2 from the block center to the block margin (recall that the block half width is $10 \mathrm{~km}$ ). If the attachment zone is $2.5 \mathrm{~km}$ thick, then $\gamma_{\mathrm{hs}}$ varies between 0 and 4 (Figs. $8 \mathrm{c}$ and $8 \mathrm{~d}$ ).

Maps of foliation and lineation, taken as the $S_{1} S_{2}$ principal plane and $\mathrm{S}_{1}$ principal axis of the finite strain ellipsoid, respectively, were produced by considering a volume of rock experiencing homogeneous deformation within the attachment zone. The wrench component $\left(\gamma_{\mathrm{w}}\right)$ is considered homogeneous across the attachment zone and the horizontal shear component $\left(\gamma_{\mathrm{hs}}\right)$ is prescribed to vary gradually from the block center to the block margins. The lateral gradient of horizontal shear is considered only qualitatively here: we 
Plan view of velocity fields at surface (stepwise line), in homogeneous shear zone (straight line), and within the transition zone (sinusoidal line)

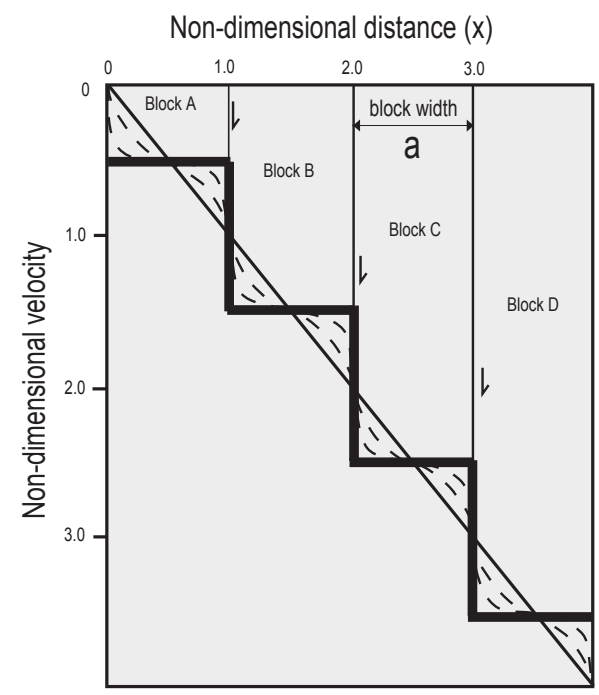

Faults equally efficient

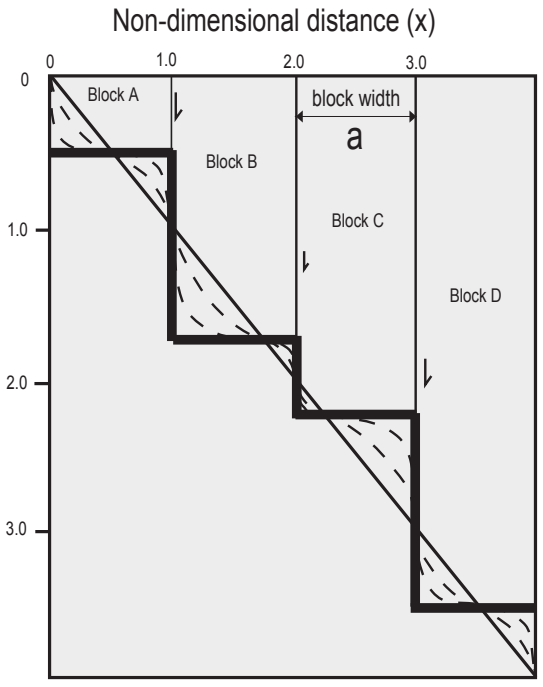

Variable fault efficiency

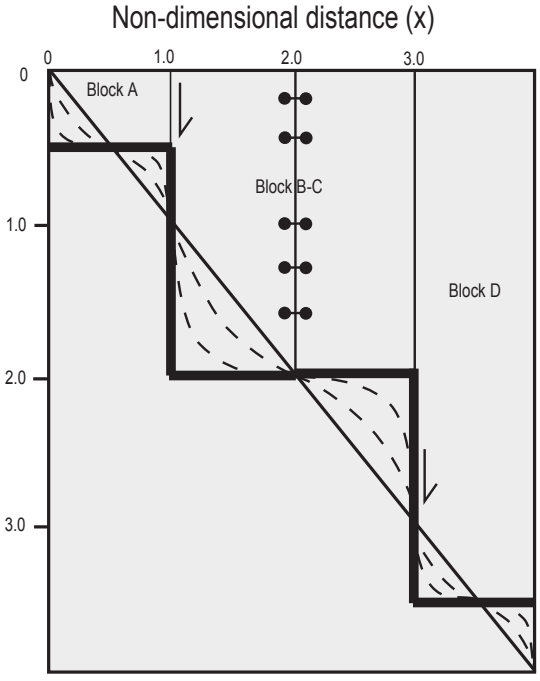

Locked fault

Fig. 10. Plan view of velocity fields (as in Fig. 6), showing the influence of fault efficiency on the deformation within the attachment zones. If fault efficiency varies with time, then the deformation in attachment zones will be complex, involving lateral sweeping of the vertical plane of no vertical velocity gradient (see text for discussion).

do not specify the exact shape of the curved lines representing the velocity gradient in the attachment zone, as shown in Figs. 8 and 9. Nevertheless, the calculated foliation and lineation orientations should be representative of the range of orientations possible within such attachment zones. Discrete solutions were calculated along the gradient of horizontal shear for specific $\gamma_{\mathrm{hs}}=0,0.5,1,1.5,2$ in the $5 \mathrm{~km}$ thick attachment zone, and $\gamma_{\mathrm{hs}}=0,1,2,3,4$ in the $2.5 \mathrm{~km}$ thick attachment zone (Figs. 8a and 8c). Similar to the case of block rotation, the solutions were obtained by assuming homogeneous strain over the entire thickness of attachment zones. However, in order to maintain strain compatibility, the foliation in the attachment zone should merge downward into the vertical foliation in the wrench zone, as illustrated schematically on the cross sections (Figs. $8 \mathrm{~b}$ and $8 \mathrm{~d}$ ). Therefore, these results are only semi-quantitative; they provide nonetheless a first-order illustration of deformation within this sort of attachment zones.

The results show that foliation appears "folded" with antiforms cresting underneath the strike-slip faults that separate the rigid blocks. The foliation in the attachment zone strikes approximately $30^{\circ}$ to the trend of the strike-slip faults. Lineation trends rotate and gradually become sub-parallel to the strike-slip fault at the block edges. Within the parts of the attachment zones directly beneath the strike-slip faults, across the crest of the antiform, deformation must be complex because the sense of shear changes abruptly by $180^{\circ}$ from top-south to top-north. Therefore, the models predict a vertical zone of discontinuity beneath the strike-slip faults, which may be rather narrow, separating regions of relatively flat fabrics and opposite sense of shear. Fabric in the shallowly dipping part of the attachment zone is strong, with $\mathrm{S}_{1} / \mathrm{S}_{3}$ approaching 20 in the case of an attachment thickness of $2.5 \mathrm{~km}$. Toward the center of the rigid blocks, the foliation becomes more steeply dipping, because of the increasing influence of wrenching. In addition, weaker fabrics $\left(\mathrm{S}_{1} / \mathrm{S}_{3} \sim 2\right)$ are predicted beneath block centers. The block-center structure is one of a synform of foliation with a fan geometry, and the sense of shear, for the geometry shown in Fig. 8, is dextral.

We also investigated the effect of large wrenching strain on fabric orientation. Figure 9 represents the case of $\gamma_{\mathrm{w}}=3$, corresponding to $\gamma_{\mathrm{hs}}=0-6$ and $0-12$ for attachment zones of thickness $\mathrm{A}=5 \mathrm{~km}$ and $2.5 \mathrm{~km}$, respectively. Results show that the antiform of foliation in the attachment zone has a "boxy" shape: for $\mathrm{A}=2.5 \mathrm{~km}$, a large region centered on the strike-slip fault is characterized by shallow foliation dips $\left(<30^{\circ}\right)$. At the crest of the antiform, the fabric is very strong, with $S_{1} / S_{3}>100$, while below the central part of the overlying rigid block, $S_{1} / S_{3} \sim 10$.

\subsection{Application of models}

One major assumption in the translational block strain modeling presented above is that below each block the velocity is constant along a vertical plane emanating from block centers (Figs. 8 and 9). This means that there should be minimal distortion and low strain expected below block centers, and the 


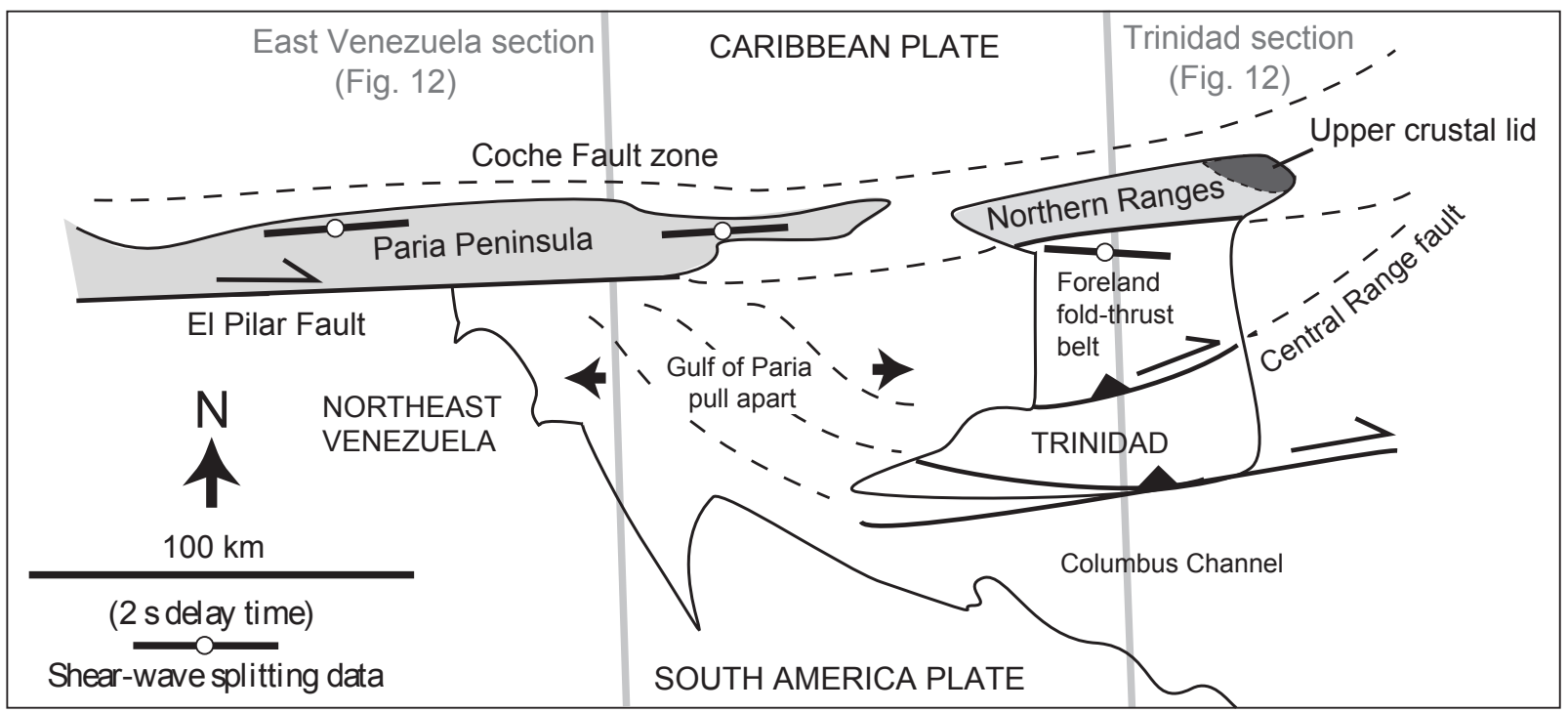

Fig. 11. Simplified geologic map of NE Venezuela and Trinidad, showing the Paria Peninsula and Northern Range uplifts, the main upper crustal structures, and the seismic anisotropy data (Russo et al., 1996). Note cross-section lines for traverses shown in Fig. 12.

strain there should be associated dominantly with wrenching. However, a number of possible factors that could complicate these results are illustrated in Fig. 10. If the bounding faults have variable efficiency over time, the assumed velocity field in the ductile deformation zone is perturbed; this in turn may cause the thickness of the deformation zone to vary, from thin zones where motion is slow to thick zones where motion is faster. Similarly, if a fault becomes locked (Fig. 10), the thickness of the deformation zone increases because the effective width of the block increases. While the bounding faults are locked, the plane of no velocity gradient is directly below the locked fault. This location coincides with the region of previous maximum velocity gradient. As strain accumulates, it is therefore unlikely that the planes of no vertical velocity gradient will remain stationary, which means that all parts of the deformation zone are likely to accumulate significant strain from the horizontal shear. Therefore, variations in fault efficiency over time should produce complex patterns of deformation under the rigid blocks, leading to complex structures that reflect variable components of wrenching and horizontal shearing. At large strains, however, one would expect mainly horizontal planar fabrics to develop subparallel to the base of the rigid blocks, especially if the zone that accommodates strain is relatively thin (a few kilometers).

\section{Case study: The Caribbean-South America plate boundary}

Molnar and Sykes (1969) first suggested that the lithosphere in the Caribbean region moves as a single, rigid plate. The northern and southern boundaries between the Caribbean and neighboring North and South America plates are generally E-W trending, wrench (strike-slip) boundaries, developed in continental and accreted arc lithosphere. Recent GPS results indicate that relative to South America (SA), the Caribbean (Ca) plate currently moves $20+/-2 \mathrm{~mm} / \mathrm{yr}$ (Weber et al., 2001a); along the El Pilar fault in central Venezuela these data predict a motion directed $090+/-3$, which is parallel to this seismically active fault. The GPS data predict motion toward $085+/-3$ in central Trinidad, which is oblique to the aseismic, 068-trending, transpressional Central Range fault (Fig. 11). El Pilar slip vectors from large earthquakes support the $090+/-3$ GPS prediction (Weber et al., 2001a, Fig. 2). Recent regional geologic analyses (Algar and Pindell, 1993) and geodetic data (Weber et al., 2001a) demonstrate that the El Pilar fault right steps into central Trinidad, forming the Gulf of Paria pull-apart basin (Fig. 11).

Pindell et al. (1998) used regional geologic data to infer $\mathrm{Ca}-\mathrm{SA}$ relative plate motion for NE Venezuela and Trinidad through the Cenozoic. Pervasive NE-SW trending Neogene contractional structures in the plate boundary zone (e.g. Perez and Aggarwal, 1981; Schubert, 1981; Kellogg and Bonini, 1982; Speed, 1985; Vierbuchen, 1984) indicate plate-scale contraction or transpression during the Neogene; a mid-Miocene thrusting event is generally recognized in Trinidad and eastern Venezuela. According to Pindell's models, from $59 \mathrm{Ma}$ to $12 \mathrm{Ma}$, the entire margin was accommodating oblique $\mathrm{Ca}-\mathrm{SA}$ convergence. The margin then began experiencing pure wrenching at $\sim 12 \mathrm{Ma}$, with coeval development of contractional and extensional structures along pull-aparts, restraining bends, and strike-slip faults that are oblique to local plate motion azimuths (e.g. the Central Range fault in Trinidad; Weber et al., 2001a).

The Trinidad-eastern Venezuela segment of the belt of deformed rocks and mountains found in the Ca-SA plate boundary zone (Fig. 11) is of interest because it preserves, in lateral arrangement and in the subsurface, structures that formed during wrenching or oblique wrenching across the 
a. THREE-DIMENSIONAL CARTOON MODEL (after Fig. 7)

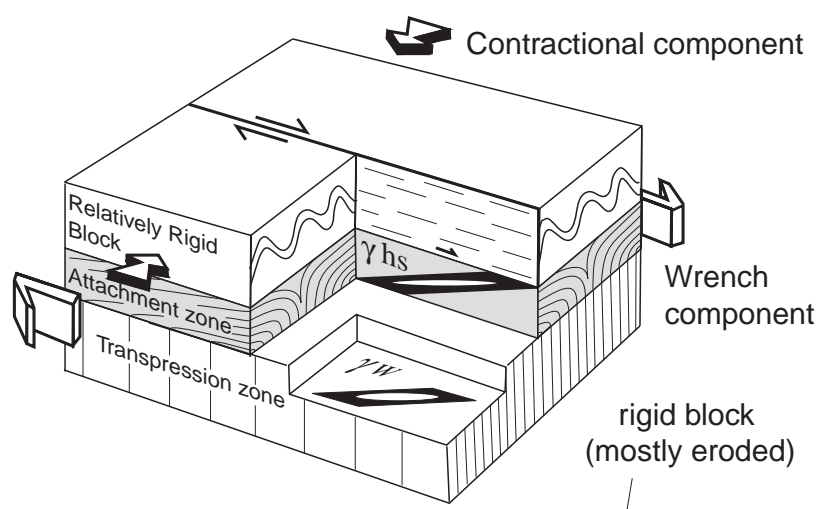

CONCEPT OF ATTACHMENT ZONE

APPLIED TO THE CARIBBEAN SOUTH AMERICA PLATE BOUNDARY

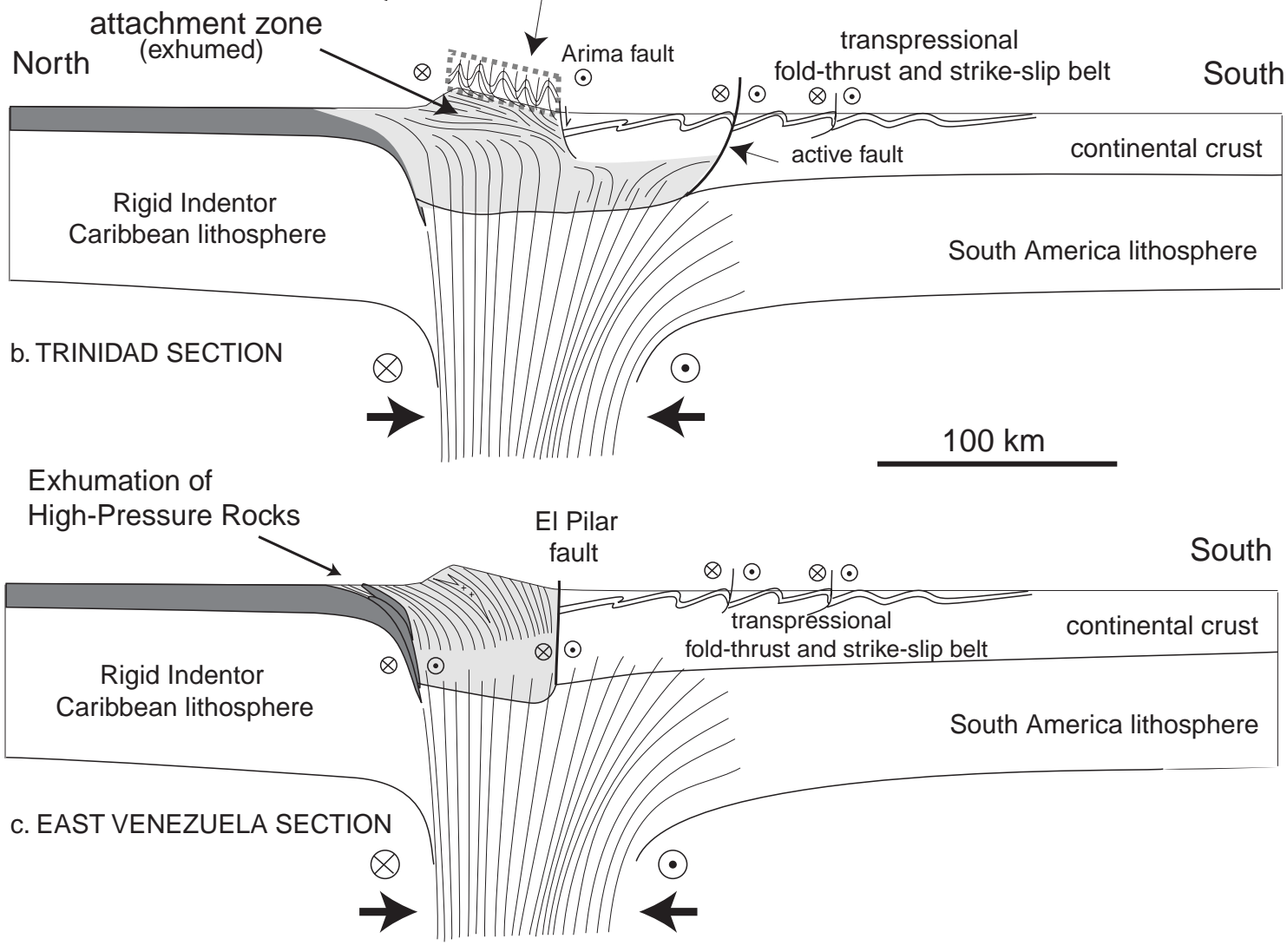

Fig. 12. (a) Cartoon showing the three-dimensional deformation associated with an attachment zone in a transpressional setting; (b) and (c) Schematic traverses, located on Fig. 11, through Trinidad and NE Venezuela showing the shear zone derived from seismic anisotropy data, the transpressional fold-thrust and strike-slip belt, and the proposed exhumed attachment zone on Trinidad.

entire thickness of the lithospheric. We distinguish three major structural units in this system: the foreland foldthrust and strike-slip belt, the hinterland metamorphic belt, and the mantle shear zone (Fig. 12). We propose that an exhumed segment of ductile crust that developed during oblique wrenching, beneath the fold-thrust and strike-slip belt, and above a mantle shear zone, i.e. an attachment zone, is exposed in the hinterland metamorphic belt. The geometry of ductile structures in this attachment zone are presented, then examined and evaluated using results from the modeling presented above.

\subsection{Mantle shear zone}

The shear-wave splitting results of Russo et al. (1996) demonstrated that the mantle beneath Trinidad and eastern Venezuela is highly anisotropic (Fig. 11). Fast shear-wave splitting directions, generally assumed to parallel the shearing direction in deformed mantle minerals, trend $\mathrm{E}-\mathrm{W}$, parallel to the plate margin and current plate motion direction. These strong mantle fabrics must reflect large mantle strains accumulated from wrenching over geologically significant periods of time. A hypothetical view of the mantle shear 
zone is shown schematically in Fig. 12.

\subsection{Fold-thrust and strike-slip belt}

The upper-crustal fold-thrust and strike-slip belt is expressed in the Serrania del Interior in Venezuela, and Central and Southern Ranges in Trinidad (Mascle et al., 1979; Kugler, 1961). This belt includes deformed sedimentary rocks of Mesozoic and Cenozoic age; based on stratigraphic data (Speed, 1985; Pindell et al., 1998; Algar and Pindell, 1993), deformation is entirely of Neogene age, and the main phase of transpression youngs from east to west. Rocks as young as Pleistocene are folded and faulted in southern Trinidad (Kugler, 1961).

Structures in the fold-thrust and strike-slip belt include NE-SW trending, upright folds and thrusts that displace passive margin and foreland basin deposits southeastward over continental South America (e.g. Mascle et al., 1979; Kugler, 1961). In Trinidad, these contractile structures are either truncated by or merge into dextral strike-slip faults in the Central Range and Southern Range (Kugler, 1961; Case and Holcombe, 1980). The regular $\sim 30 \mathrm{~km}$ separation between the Northern, Central, and Southern ranges suggests the presence of upper-crustal blocks separated by strike-slip faults on this length scale. According to the models presented above, the proposed $\sim 30 \mathrm{~km}$ block width suggests that the thickness of a ductile attachment zone formed in this setting could be as thick as $\sim 10 \mathrm{~km}$, given a newtonian rheology, or less than $10 \mathrm{~km}$ assuming a power-law rheology.

\subsection{Hinterland belt}

Coastal mountains that make up the internal part or hinterland of the Ca-SA orogen lie north of the fold-thrust and strike-slip belt. Avé Lallemant (1997) synthesized the geologic history of this belt. In the Araya Peninsula, Venezuela, oceanic and subduction-related terranes, which contain highpressure mineral assemblages, are exposed. Greenschistand subgreenschist-grade lateral equivalents of South America passive margin deposits are present in Paria in eastern Venezuela, and in the Northern Range of Trinidad (Frey et al., 1988; Algar and Pindell, 1993; Weber et al., 2001b). We propose that a ductile attachment zone is at exposure level in this eastern portion of the hinterland belt (Fig. 12).

\subsection{Northern Range-Paria exhumed attachment zone}

In marked contrast to the upright, shallow-level structures in the fold-thrust and strike-slip belt, rocks in the western and central Northern Range contain pervasive, shallowly dipping, E-W striking foliations and strong E-W subhorizontal stretching lineations (Gonzalez de Juana et al., 1972; Weber et al., 2001b) (Fig. 13), which have patterns that are similar to the model fabrics presented in Figs. 8 and 9. Sense of shear in these rocks is ambiguous and the focus of on-going studies. On Paria to the west, foliation dip increases and lineation is consistently oblique to the SW, with a sense of shear preliminarily recognized as top to $\mathrm{SW}$, with a dextral-normal shearing component, although the documentation is sparse.

The Northern Range-Paria structures represent the accumulation of high strain during ductile deformation. Weber et al. (2001b) documented that deformation temperatures increase from $200-300^{\circ} \mathrm{C}$ to $300-400^{\circ} \mathrm{C}$ from east to west across the Northern Range. Zircon fission tracks are reset in the western Northern Range, but not in the eastern Northern Range (see below). Calcite microstructural types (Burkhard, 1993; Weber et al., 2001b) also vary from type $\mathrm{V}\left(>300^{\circ} \mathrm{C}\right)$ to type III $\left(>200^{\circ} \mathrm{C},<250^{\circ} \mathrm{C}\right)$ along this trend. In the central Northern Range, quartz-rich metasedimentary rocks contain microstructures indicative of dislocation creep regime 2 of Hirth and Tullis (1992); detrital quartz grains are stretched homogeneously, and recrystallized at grain edges by subgrain rotation. In contrast, the quartzose metasedimentary rocks of the western Northern Range are entirely recrystallized in dislocation creep regime 3 (Hirth and Tullis, 1992) and display evidence of grain boundary migration. This exhumed regime $2-3$ transition likely corresponds to a temperature boundary.

Abstracts from an unpublished ${ }^{40} \mathrm{Ar} /{ }^{39} \mathrm{Ar}$ study of the rocks from the Northern Range and Paria (Foland et al., 1992; Foland and Speed, 1992) report that spectra obtained from some of the metamorphic white micas gave Neogene $(\sim 25 \mathrm{Ma})$ ages. Such ages are consistent with and pre-date fission-track cooling ages from the Northern Range. Zircon fission-track data indicate that during exhumation rocks in the western and central Northern Range cooled through $\sim 230-330^{\circ} \mathrm{C}$ at $\sim 12 \mathrm{Ma}$ (Algar, 1993; Algar et al., 1998; Weber et al., 2001b). Zircon fission tracks are unreset in the eastern Northern Range; a single reset apatite fission-track age there indicates that these rocks cooled through $\sim 110^{\circ} \mathrm{C}$ at $22 \mathrm{Ma}$ (Weber et al., 2001b). No published fission track ages or ${ }^{40} \mathrm{Ar} /{ }^{39} \mathrm{Ar}$ ages exist for Paria.

Weber et al. (2001b) interpreted that the rocks in the eastern Northern Range comprise a non-eroded segment of the upper-crustal, fold-thrust and strike-slip belt that structurally overlies higher-grade rocks in the western and central Northern Range. Rocks in this upper-crustal lid (Fig. 11) have relatively low deformation temperatures $\left(200-330^{\circ} \mathrm{C}\right)$. Excluding the rocks exposed in the northeastern corner of the Northern Range near Sans Souci, Toco, and Galera Point, these upper-crustal rocks have upright D1 fabrics, and NESW strikes (Weber et al., 2001b), similar to those in the foldthrust and strike-slip belt proper further south. Rocks with relatively low deformation temperatures and upright fabrics, probably once part of the transition to the upper-crustal lid, also occur in down-dropped fault blocks along the southern foot of the Northern Range (Weber et al., 2001b) (Fig. 11) and along the southern front of the coastal range in Paria (Maresh, 1979).

The upright and low-grade over flat and high-grade structure in the Northern Range, with lineations parallel to the belt, is similar to the suprastructure-infrastructure architecture in the Pyrenees, first described by De Sitter and Zwart (1960) (Fig. 11). It may also be a fundamental feature char- 


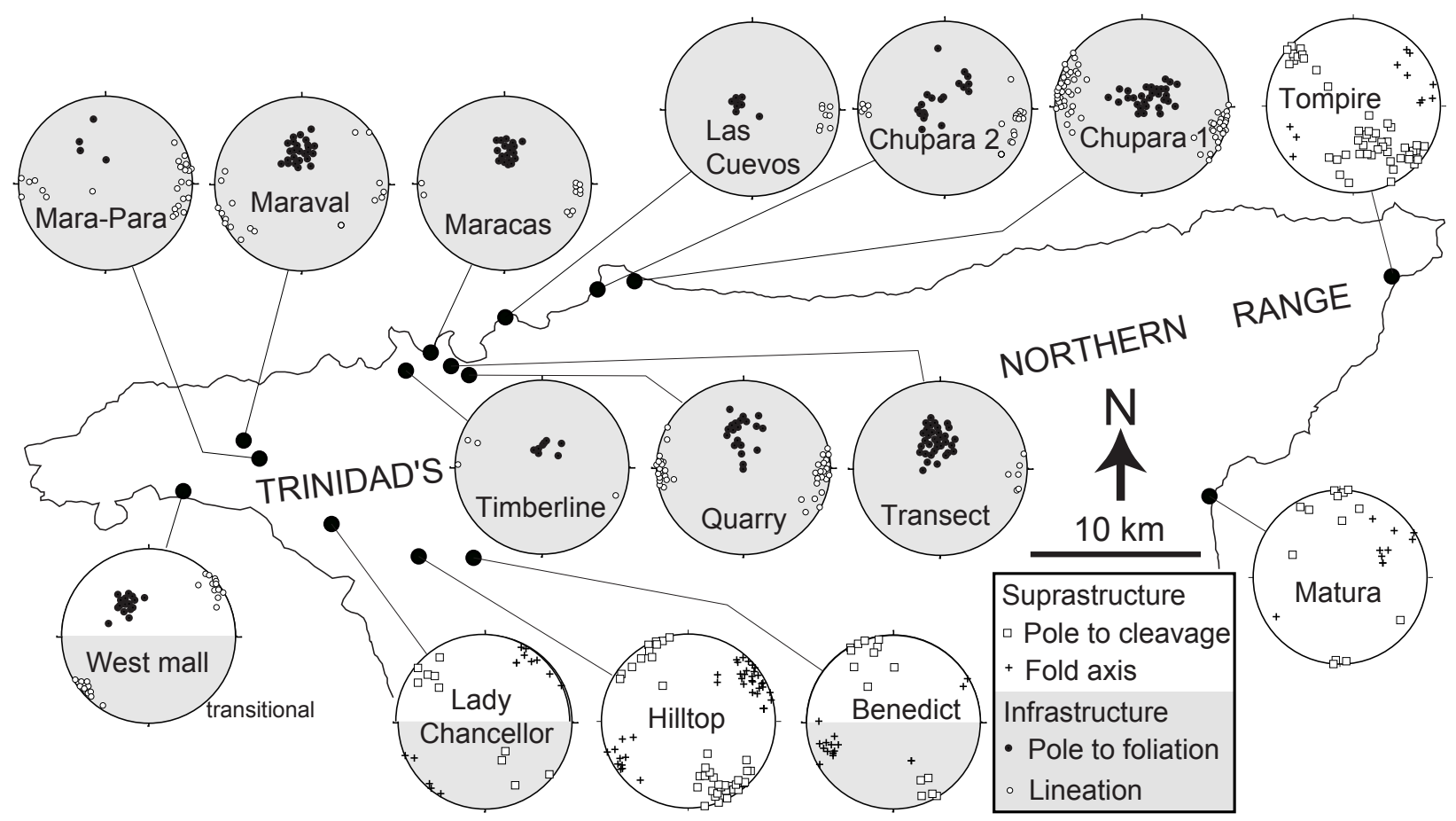

Fig. 13. Lower hemisphere stereoplots show shallowly dipping foliation and $\sim \mathrm{E}-\mathrm{W}$ lineations in the western region of the Northern Range (infrastructure, grey stereonets), and upright structures (fold axial plane cleavage) in the suprastructure domains (white stereonets). White and grey stereonets represent transitional regions between infra- and suprastructure.

acteristic of other orogenic belts developed during oblique wrenching. The origin of the suprastructure-infrastructure architecture in the Pyrenees is still under debate (e.g. Carreras and Capela, 1994, 1995; Garcia-Sansegundo, 1996; and references therein). Our ideas for vertical strain partitioning of lithospheric layers in the Ca-SA oblique wrench zone may apply.

The foliation and lineation patterns present in the western and central Northern Range have proven problematic to explain in this specific plate tectonic setting, which is known to have been dominated by wrenching. The models presented above offer some new insights. The major shortcoming in applying these models here is that they do not account for upper-crustal block shortening normal to the bounding wrench faults. We infer that significant boundary normal shortening has occurred in these rocks from the structures observed in the upper crustal lid preserved at the eastern end of the Northern Range (e.g. Weber et al., 2001b) and from correlative structures in the fold-thrust and strike-slip belt. If such shortening was accommodated by transpression, with margin-normal shortening and vertical thickening, foliation dips in the attachment zone would likely steepen. However, at high total displacement, which was certainly reached in Northern Range-Paria case, wrenching and horizontal shearing should predominate and control foliation and lineation orientation.

The fairly consistently oriented and subhorizontal lineations (Fig. 13) are most like those in the high-wrench-strain translating block model (Fig. 9). The consistent E-W North- ern Range lineation trends are subparallel to present-day plate motion (Weber et al., 2001a) and the fast shear-wave splitting direction in the Ca-SA mantle shear zone (Russo et al., 1996) (Fig. 11), suggests coupling between the lithospheric layers. The relatively uniform E-W strike and shallow dip of the foliation in the western and central Northern Range (Fig. 11) resembles most closely those in the highwrench-strain, thin-attachment-zone model (Figs. 9c and 9d). Steepening of foliation toward Paria to the west may reflect the "anticlinal" structure of an attachment zone (Figs. 8 and 9).

\section{Conclusions}

At wrenching plate boundaries, shearing is essentially orthogonal to the rheologic layers of the lithosphere (brittle upper crust, ductile lower crust, and upper mantle). Deformation between the upper crust that deforms largely by translation and rotation of relatively rigid blocks separated by strike-slip faults, and the lower crust that deforms by ductile flow, is achieved in an attachment zone where strain continuity is maintained. Strain modeling of attachment zones beneath rotating blocks predicts the occurrence of shallowly dipping, radially trending foliations and close to concentric lineations; however, if block rotation is driven from below, the deformation in the attachment zone is dominated by the wrench-produced fabrics, with steeper and more consistently trending foliations and shallowly plunging lineations. In attachment zones beneath translated blocks, foliation de- 
scribes an antiform cresting below the upper crustal strikeslip faults and a fanning synform beneath the blocks center. This antiform is presumably split by a vertical zone of discontinuitty across which the sense of shear is reversed. Lineations are oriented at a low angle to the wrench zone, especially beneath blocks margins. Another characteristic of attachment zones developed beneath translating blocks is the strong finite strain gradients that exist, from relatively modest wrench-related strain below the blocks centers to extremely large strain values due to the horizontal shearing near the blocks margins.

The linear belt of greenschist-grade metamorphic rocks in Trinidad's Northern Ranges and eastern Venezuela's Paria Peninsula displays foliations and lineations that are consistent with the patterns predicted in an attachment zone. This attachment zone developed beneath translating upper crustal blocks during Neogene wrenching, or highly oblique convergence between the Caribbean and South America plates.

Acknowledgements. We acknowledge support from NSF-EAR 9607018 and Grant-in-Aid 17904 from the University of Minnesota Graduate School. Discussions with Jean-Pierre Burg, Donna Whitney, and Terry Pavlis during the early phases of this work were stimulating and encouraging. We are grateful to Niko Froitzheim and Karel Schulmann for their careful and constructive reviews.

\section{References}

Algar, S. T.: Structural, stratigraphic, and thermo-chronological evolution of Trinidad, Ph. D. Thesis, Dartmouth College, 1993.

Algar, S. and Pindell, J.: Structure and deformation history of the Northern Range of Trinidad and adjacent areas, Tectonics, 12, 814-829, 1993.

Avé Lallemant, H. G.: Transpression, displacement partitioning, and exhumation in the eastern Caribbean/South American plate boundary zone, Tectonics, 16, 272-289, 1997.

Bourne, S. J., England, P. C., and Parsons, B.: The motion of crustal blocks driven by flow of the lower lithosphere and implications for slip rates of continental strike-slip faults, Nature, 391, 655659, 1998a.

Bourne, S. J., Arnadottir, T., Beavan, J., Darby, D. J., England, P. C., Parsons, B., Walcott, R. I., and Wood, P. R.: Crustal deformation of the Marlborough fault zone in the South Island of New Zealand geodetic constraints over the interval 1982-1994, J. Geophys. Res., 103-12, 30 147-30 165, 1998 b.

Burkhard, M.: Calcite twins: their geometry, appearance, and significance as stress-strain markers and indicators of tectonic regime: a review, J. Struct. Geol., 15, 351-368, 1993.

Carreras, J. and Capela, I.: Tectonic levels in the Paleozoic basement of the Pyrenees: a review and new interpretation: Reply, J. Struct. Geol., 17, 1493-1495, 1995.

Carreras, J. and Capela, I.: Tectonic levels in the Paleozoic basement of the Pyrenees: a review and new interpretation, J. Struct. Geol., 17, 1509-1524, 1994.

Case, J. E. and Holcombe, T. L.: Geologic-tectonic map of the Caribbean region, US Geol. Survey Miscell. Invest. Map I-1100, scale 1:2500 000, 1980.

De Sitter, L. U. and Zwart, H. J.: Tectonic development in supraand infrastructures of mountain chains, Proc. $21^{\text {st }}$ Int. Cong., Copenhagen, 18, 248-256, 1960.
England, P. G. and Wells, R. E.: Neogene rotations and quasicontinuous deformation of the Pacific Northwest continental margin, Geology, 19, 978-981, 1991.

Foland, K. A., Speed, R., and Weber, J.: Geochronologic studies of the hinterland of the Caribbean orogen of Venezula and Trinidad, Geological Society of America Abstracts with Programs, 24, A148, 1992.

Foland, K. A. and Speed, R. C.: Geochronology of metamorphic rocks of the Northern Range. Symposium on regional structure and tectonic evolution of northern Trinidad and vicinity, Programme and Abstracts, Geological Society of Trinidad and Tobago, 11, 1992.

Fossen, H.: Linear fabrics in the Bergsdalen Nappes, southwest Norway: implications for deformation history and fold development, Norsk Geologisk Tidsskrift, 73, 95-108, 1993.

Fossen, H. and Tikoff, B.: The deformation matrix for simultaneous simple shearing, pure shearing, and volume change, and its application to transpression/transtension tectonics, J. Struct. Geol., 15, 413-422, 1993.

Frey, M., Saunders, J., and Schwander, H.: The mineralogy and metamorphic geology of low- grade metasediments, Northern Range, Trinidad, Journal of the Geological Society of London, 145, 563-575, 1988.

Garcia-Sansegundo, J.: Hercynian structure of the Axial Zone of the Pyrenees: the Aran Valley cross-section (Spain-France), J. Struct. Geol., 18, 1315-1325, 1996.

Ghosh, S. K. and Ramberg, H.: Reorientation of inclusions by combination of pure and simple shear, Tectonophysics, 34, 1-70, 1976.

Gonzalez de Juana, C., Munoz, N. G., and Vignali, M.: Reconocimiento Geologia de la Peninsula de Paria, Venezuela, Memoria Cuarto Congresso Geologico Venezolana, Tomo III Ministereo de Minas e Hidrocarburos, Direccion de Geologica, Republica de Venezuela, Boletin de Geologica, Publicacion Especial, 5, 1549-1588, 1972.

Gratier, J. P., Renard, F., and Labaume P.: How pressure solution and fractures interact in the upper crust to make it behave in both a brittle and viscous manner, J. Struct. Geol., 21, 1189-1197, 1999.

Hirth, G. and Tullis, J.: Dislocation creep regimes in quartz aggregates, J. Struct. Geol., 14, 145-160, 1992.

Karato, S.-I. and Jung, H.: Water, partial melting and the origin of the seismic low velocity and high attenuation zone in the upper mantle, Earth Plan. Sci. Letters., 157, 193-207, 1998.

Karato, S., Zhang, S., Zimmerman, M. E., Daines, M. J., Kohlstedt, D. L.: Experimental studies of shear deformation of mantle materials: Towards a structural geology of the mantle, Pure appl. geophys., 151, 589-603, 1998.

Karlstrom, K. E. and Williams, M. L.: Heterogeneity of the middle crust: Implications for strength of continental lithosphere, Geology, 26, 815-818, 1998.

Kellogg, J. N. and Bonini, W. E.: Subduction of the Caribbean plate and basement uplifts in the overriding South American plate, Tectonics, 1, 251-276, 1982.

Kohlstedt, D. L., Evans, B., and Mackwell, S. J.: Strength of the lithosphere: Constraints imposed by laboratory experiments, J. Geophys. Res., 100, 17 587-17 602, 1995.

Kugler, H. G.: Geological map and sections of Trinidad. Scale 1:100 000, Orell Fussli, Zürich (also in: Kugler, H. G.: Treatise on the Geology of Trinidad, compiler, Part 2 or part of Part 3, Natural History Museum, Basel, Switzerland), 1961.

Luyendik, B., Kammerling, M., and Terres, R.: Geometric model 
for Neogene crustal rotations in southern California, Geological Society of America Bulletin, 91, 211-217, 1980.

Maresh, W. V.: The significance of employing key minerals and mineral assemblages for a regional correlation of metamorphic rocks in the southeastern Caribbean, Proceedings of the 4th Latin American Geological Congress, Trinidad and Tobago, 1979.

Mascle, A., Tremolieres, P., and Wozniak, W. H.: Neogene compressional events on the North Venezuelan margin, Syn. Geol. et Geochim., 7010, Inst. Fr. Pet., France, 1979.

Merle, O. and Gapais, D.: Strains in thrust-wrench zones, J. Struct. Geol., 19, 1011-1014, 1997.

Molnar, P.: Brace-Goetze strength-profiles, the partitioning of strike-slip and thrust faulting at zones of oblique convergence, and the stress-heat flow paradox of the San Andreas fault, in: Evans, B. and Wong, T.-F. (Eds.): Fault Mechanics and Transport Properties of Rocks, Academic Press, 435-459, 1992.

Molnar, P.: Continental tectonics in the aftermath of plate tectonics, Nature, 335, 131-137, 1988.

Molnar, P., Anderson, H. J., Audoine, E., Eberhart-Phillips, D., Gledhill, K. R., Klosko, E. R., McEvilly, T. V., Okaya, D., Savage, M. K., Stern, T., and Wu, F. T.: Continuous deformation versus faulting through the continental lithosphere of New Zealand, Science, 286, 516-519, 1999

Molnar, P. and Sykes, L.: Tectonics of the Caribbean and Middle America regions from focal mechanisms and seismicity, Geological Society of America Bulletin, 80, 1639-1684, 1969.

Özalaybey, S. and Savage, M. K.: Shear-wave splitting beneath western United States in relation to plate tectonics, J. Geophys. Res., 100, 18 135-18 149, 1995.

Perez, O. J. and Aggarwal, Y. P.: Present day tectonics of the southeastern Caribbean plate and northeastern Venezuela, J. Geophys. Res., 86, 10 791-10 804, 1981.

Pindell, J. L., Higgs, R., and Dewey, J.: Cenozoic palinspastic reconstruction, paleogeographic evolution, and hydrocarbon setting of the northern margin of South America, in: Pindell, J. L. and Drake, C. (Eds.): Paleogeographic evolution and non-glacial eustasy, northern South America, Society of Economic Paleontologists and Mineralogists Special Publication, 58, 1998.

Ramsay, J. G. and Huber, M. I.: The Techniques of Modern Structural Analysis - Vol. 1, Strain Analysis, New York, Academic Press, 1983.

Russo, R. M., Silver, P. G., Franke, M., Ambeh, W. B., and James, D. E: Shear-wave splitting in northeast Venezuela, Trinidad, and the eastern Caribbean, Physics of the Earth and Planetary Interiors, 95, 251-275, 1996.
Savage, J. C., Svarc, J. L., and Prescott, W. H.: Geodetic estimates of fault slip rates in the San Francisco Bay area, Journal of Geophysical Research, 104, 4995-5002, 1999.

Schubert, C.: Are the Venezuelan fault systems part of the southern Caribbean plate boundary, Geol. Rundsch., 70, 542-551, 1981.

Silver, P. G.: Seismic anisotropy beneath the continents: Probing the depths of geology, Annual Review of Earth and Planetary Sciences, 24, 385-432, 1996.

Snoke, A. W., Tullis, J., and Todd, V. R.: Fault-Related Rocks - A Photographic Atlas, Princeton University press, Princeton, New Jersey, 617 pp, 1998.

Speed, R. C.: Cenozoic collision of the Lesser Antilles arc and continental South America and the origin of the El Pilar fault, Tectonics, 4, 41-69, 1985.

Sylvester, A. G.: Strike-slip faults, Geol. Soc. Am. Bull., 100, 1666-1703, 1988.

Teyssier, C. and Tikoff, B.: Strike-slip partitioned transpression of the San Andreas fault system: a lithospheric scale approach, in: Holdsworth, R. E, Strachan, R. A., and Dewey, J. F. (Eds.): Continental transpression and transtension tectonics, Geol. Soc. London Sp. Publ., 135, 143-158, 1998.

Thompson, A. B., Schulmann, K., and Jezek, G.: Thermal evolution and exhumation in obliquely convergent (transpressive) orogens, Tectonophysics, 280, 171-184, 1997.

Tikoff, B. and Fossen, H.: Simultaneous pure and simple shear: the unified deformation matrix, Tectonophysics, 217, 267-283, 1993.

Tikoff, B. and Fossen, H.: Computer applications for visualization and calculation of deformation, in: DePaor, D.: Microcomputers and Structural Geology, Pergamon, 75-96, 1996.

Tikoff, B. and Teyssier, C.: Strain of displacement-field partitioning in transpressional orogens, J. Struct. Geol., 16, 1575-1588, 1994.

Vierbuchen, R. C.: The geology of the El Pilar fault zone and adjacent areas in northeastern Venezuela, in: Bonini, W. E. (Ed.): The Caribbean-South American plate boundary and regional tectonics, Geological Society of America, Boulder, 189-212, 1984.

Weber, J. C., Dixon, T. H., DeMets, C., Ambeh, W. B., Jansma, P., Mattioli, G., Saleh, J., Sella, G., Bilham, R., and Perez, O.: GPS estimates of relative motion between the Caribbean and South American plate, and geological implications for Trinidad and Venezuela, Geology, 29, 75-78, 2001a.

Weber, J. C., Ferrill, D. A., and Roden-Tice, M. K.: Calcite and quartz microstruc tural geothermometry of low-grade sedimentary rocks, Northern Range, Trinidad, J. Struct. Geol., 23, 93$112,2001 \mathrm{~b}$. 